\title{
A review of the Barsine perpallida-B. yuennanensis species-group, with descriptions of six new species (Lepidoptera: Erebidae: Arctiinae)
}

\author{
Anton V. VOLYNKIN ${ }^{1,2, *)}$, Karel ČERNÝ ${ }^{3)} \&$ Si-yao HUANG ${ }^{4)}$ \\ 1) Altai State University, Lenina Av., 61, RF-656049, Barnaul, Russia; e-mails: volynkin_a@mail.ru, barsine@yahoo.com \\ 2) National Research Tomsk State University, Lenina Av., 36, RF-634050, Tomsk, Russia \\ ${ }^{3)}$ Tiergartenstrasse 27, A-6020 Innsbruck, Austria; e-mail: natura.cerny@aon.at \\ 4) Department of Entomology, College of Agriculture, South China Agricultural University, Guangzhou 510642, Guangdong, China; \\ e-mail: huangsiyao2007@aliyun.com \\ ${ }^{*}$ Corresponding author
}

Accepted:
$18^{\text {th }}$ June 2019
Published online:
$3^{\text {rd }}$ July 2019

Zoobank: http://zoobank.org/urn:lsid:zoobank.org:pub:D95019E7-AA94-4E21-964E-DFF57E9EF272

(C) 2019 The Authors. This work is licensed under the Creative Commons Attribution-NonCommercial-NoDerivs 3.0 Licence.

\begin{abstract}
The Barsine perpallida-B. yuennanensis species-group is reviewed. Six new species, B. biformis Volynkin \& Černý, sp. nov. (North Thailand and North Vietnam), B. laszloi Volynkin \& Černý, sp. nov. (Nepal), B. hausmanni Volynkin \& Černý, sp. nov. (North Thailand), B. andromeda Volynkin, Černý \& Huang, sp. nov. (China: Shaanxi and Sichuan), B. eurydice Volynkin \& Černý, sp. nov. (North Vietnam), and B. dao Volynkin, Černý \& Huang, sp. nov. (North Vietnam and China: Yunnan), are described. All species treated are subdivided into five subgroups: B. biformis, B. perpallida, B. favicollis, B. hausmanni, and B. yuennanensis subgroups. Four new combinations are established: Barsine hololeuca (Hampson, 1895), comb. nov., B. ruficollis (Fang, 1991), comb. nov., Barsine nigrovena (Fang, 2000), comb. nov. (all three from Miltochrista Hübner, [1819]), and B. flavicollis (Moore, 1878), comb. nov. (from Mahavira Moore, 1878). A lectotype for Mahavira flavicollis Moore, 1878 is designated. One new synonymy is established: B. perpallida $($ Hampson, 1900) = Diacrisia porthesioides Rothschild, 1910, syn. nov. Adults, male and female genitalia of all species are illustrated.
\end{abstract}

Key words. Lepidoptera, Erebidae, Arctiinae, Lithosiini, lectotype, new combination, new species, species-group, species-subgroup, China, Thailand, Vietnam, Asia

\section{Introduction}

Barsine Walker, 1854 is a large genus of lichen-moths (family Erebidae, subfamily Arctiinae, tribe Lithosiini, subtribe Nudariina) widespread in the Oriental and Palaearctic Regions. Species of the genus are usually red, bright yellow with red markings, or whitish with blackish pattern. Species of the present genus were usually lumped in Miltochrista Hübner, 1819. There are also several species with pale yellow or whitish coloration and reduced pattern. Due to the external similarity these species were treated as the Barsine perpallida-B. yuennanensis speciesgroup during our studies.

Barsine perpallida (Hampson, 1900) was described from northeastern India (MOORE 1878) and later reported from China (Yunnan) and Thailand (FANG 1991, 2000; ČERNÝ \& PINRATANA 2009). Examination of the genitalia of the specimens from Thailand proved that they belong to another, yet undescribed species not related to B. perpallida. Barsine hololeuca (Hampson, 1895) comb. nov. and $B$. flavicollis (Moore, 1878) comb. nov. are currently known only from the types collected in Bhutan and northeastern India, respectively. During examination of extensive Lithosiini materials deposited in the collection of MWM/ZSM (Munich), a series of pure white Barsine specimens from central Nepal was found. Their male genitalia are similar to those of the holotypes of B. hololeuca and B. flavicollis. Nevertheless, these specimens have significant external and genital differences from both related species and belong to 
another undescribed species. Barsine yuennanensis (Daniel, 1952) and B. ruficollis (Fang, 1991) were described from China, Yunnan province. Barsine yuennanensis was reported from northern Thailand by ČERnÝ \& PinRATANA (2009). We found specimens externally very similar to $B$. yuennanensis and B. ruficollis in MWM/ZSM. All three populations from Thailand and Vietnam show significant genital differences from the externally similar Chinese species and also belong to new, yet undescribed species. In addition, during examination of MWM/ZSM collection we found one more patternless species of Barsine from the Chinese provinces of Shaanxi and Sichuan. This species is also new to science and has genitalia similar to those of $B$. yuennanensis.

Female of $B$. nigrovena (Fang, 2000), comb. nov. is also similar externally to that of $B$. yuennanensis and its allies, but male has forewing pattern different from that of other species of the group due to the presence of broad blackish shades on both wings. The holotype genital preparation of $B$. nigrovena is lost and the drawing of male genitalia presented in the original description (FANG 2000: fig. 55) is poorly informative; therefore, the placement of this interesting species within the genus was unclear for almost twenty years. Fortunately, during the recent collecting trip to the type locality of $B$. nigrovena three male specimens were collected by the third author of the present paper. Examination of their genitalia proved close relationship of B. nigrovena and B. yuennanensis.

This paper is devoted to a review of this complex of species (so called the Barsine perpallida-B. yuennanensis species-group) and description of six new species. However, all externally similar species mentioned above clearly belong to several, not closely related subgroups also erected below.

\section{Material and methods}

The genitalia were dissected and mounted in euparal on glass slides. The photos of adults were taken using a Nikon D3100/AF-S camera equipped with a Nikkor, 18-55 $\mathrm{mm}$ lens. The photos of genitalia were taken by the same camera attached to a stereo microscope with an LM-scope adapter. All photos were processed using Adobe Photoshop CC 2018® software. The terminology of the genitalia structure is given according to VOLYNKIN \& ČERNÝ (2016).

The material examined is deposited in the following collections:

CKC Karel Černý’s private collection, Innsbruck, Austria

IZCAS Institute of Zoology of Chinese Academy of Sciences, Beijng, China;

MWM/ZSM Museum Witt Munich / the Bavarian State Collection of Zoology (Museum Witt München / Zoologische Staatssammlung München), Munich, Germany;

NHMUK Natural History Museum (formerly British Museum of Natural History), London, United Kingdom;

SCAU South China Agricultural University, Guangzhou, China;

ZFMK Zoological Research Museum Alexander Koenig (Zoologisches Forschungsmuseum Alexander Koenig), Bonn, Germany;

ZMB Museum of Natural History (Museum für Naturkunde), Berlin, Germany;

ZSM Bavarian State Collection of Zoology (Zoologische Staatssammlung München), Munich, Germany.
Results

Checklist of the Barsine perpallida-B. yuennanensis species-group

Barsine biformis subgroup

B. biformis Volynkin \& Černý, sp. nov.

Barsine perpallida subgroup

B. perpallida (Hampson, 1900)

= Korawa pallida Moore, 1878

= Diacrisia porthesioides Rothschild, 1910, syn. nov.

Barsine flavicollis subgroup

B. flavicollis (Moore, 1878), comb. nov.

B. hololeuca (Hampson, 1895), comb. nov.

B. laszloi Volynkin \& Černý, sp. nov.

Barsine hausmanni subgroup

B. hausmanni Volynkin \& Černý, sp. nov.

Barsine yuennanensis subgroup

$B$. andromeda Volynkin, Černý \& Huang, sp. nov.

B. dao Volynkin, Černý \& Huang, sp. nov.

$B$. eurydice Volynkin \& Černý, sp. nov.

B. nigrovena (Fang, 2000)

B. ruficollis (Fang, 1991), comb. nov.

B. yuennanensis (Daniel, 1952)

\section{Barsine biformis subgroup}

Diagnosis. The subgroup is characterized by the presence of a large, stick-like dentate subbasal process of valva costa, its strongly broadened, bilobate distal saccular process, bilobate $1^{\text {st }}$ medial diverticulum with granulation only and $3^{\text {rd }}$ medial diverticulum with granulation only.

\section{Barsine biformis Volynkin \& Černý, sp. nov.}

$$
\text { (Figs 1-4, 33, 48) }
$$

Korawa perpallida (misidentification): ČernÝ \& PinRatana (2009): 77 (species account), pl. 16, figs 151a-151c (adults).

Type locality. Thailand, Changwat Nan, $30 \mathrm{~km} \mathrm{E}$ of Pua, ca. $19^{\circ} 9^{\prime} \mathrm{N}$ $101^{\circ} 15^{\prime} \mathrm{E}, 1700 \mathrm{~m}$.

Type material. HoLotyPe (Figs 1, 33): 今, "Thailand / Changwat Nan / 30 km E of Pua, 1700 m, 14-15.IX.1999 / leg. A. Szabó \& Z. Czere”, slide MWM 31351 Volynkin (MWM/ZSM). PARATYPES: THAILAND: $6 \precsim \delta$ 4 오, same locality as in the holotype, but 8.iv.1998, leg. Tibor Csővári \& Pál Stéger, slide ZSM Arct. 155/2017 9 Volynkin (MWM/ZSM); 1 ภ, Thailand, Changwat Nan, $30 \mathrm{~km}$ E of Pua 1700 m, 6.iv.1996, leg. Tibor Csővári \& Pál Stégér (CKC); 5 ô 3 q 9 , N Thailand, Chiang Mai, Fang, Doi Ang Khang, 1425 m, 29 $9^{\circ} 4^{\prime} 11^{\prime \prime} \mathrm{N}, 99^{\circ} 2^{\prime} 32^{\prime \prime} \mathrm{E}, 19-23 . i x .2006$, leg. T. Ihle (CKC); 1 , same locality and collector, but 11-15.ix.2006 (CKC);

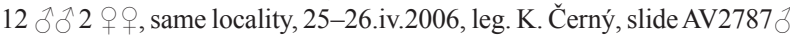
Volynkin (CKC); 1 , N Thailand, Mae Hong Son, 10 km E Khun Yuam, $950 \mathrm{~m}, 18^{\circ} 47^{\prime} 10^{\prime \prime} \mathrm{N}, 98^{\circ} 3^{\prime} 4^{\prime \prime} \mathrm{E}$, forest edge, 1.v.2006, leg. K. Černý (CKC). VIETNAM: 4 , N Vietnam, $1400 \mathrm{~m}$, Mai-chau, primary forest, 40 km SE Moc-chau, 20.50'N 104.50'E, 07-15.iv.1995, leg. Sinjaev \& local collectors, slide MWM 31541 (む) Volynkin (MWM/ZSM).

Diagnosis. The species has two forms, patterned (Figs 1,2) and patternless (Figs 3, 4), occurring sympatrically. Externally, the patternless specimens of $B$. biformis are similar to $B$. perpallida (Figs 5-7), but differ in their smaller size, slightly darker forewings and principally different male and female genitalia structures. The broadened distal saccular process of B. biformis (Fig. 33) resembles those of B. delicia 


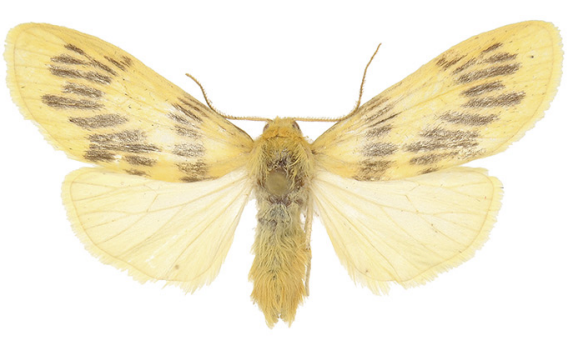

1

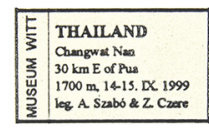

B. biformis sp. n., HT $\hat{\sigma}$

3
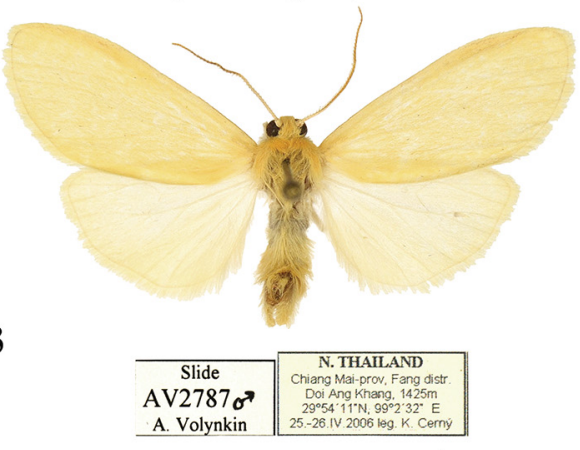

B. biformis sp. n., PT ${ }^{\lambda}$
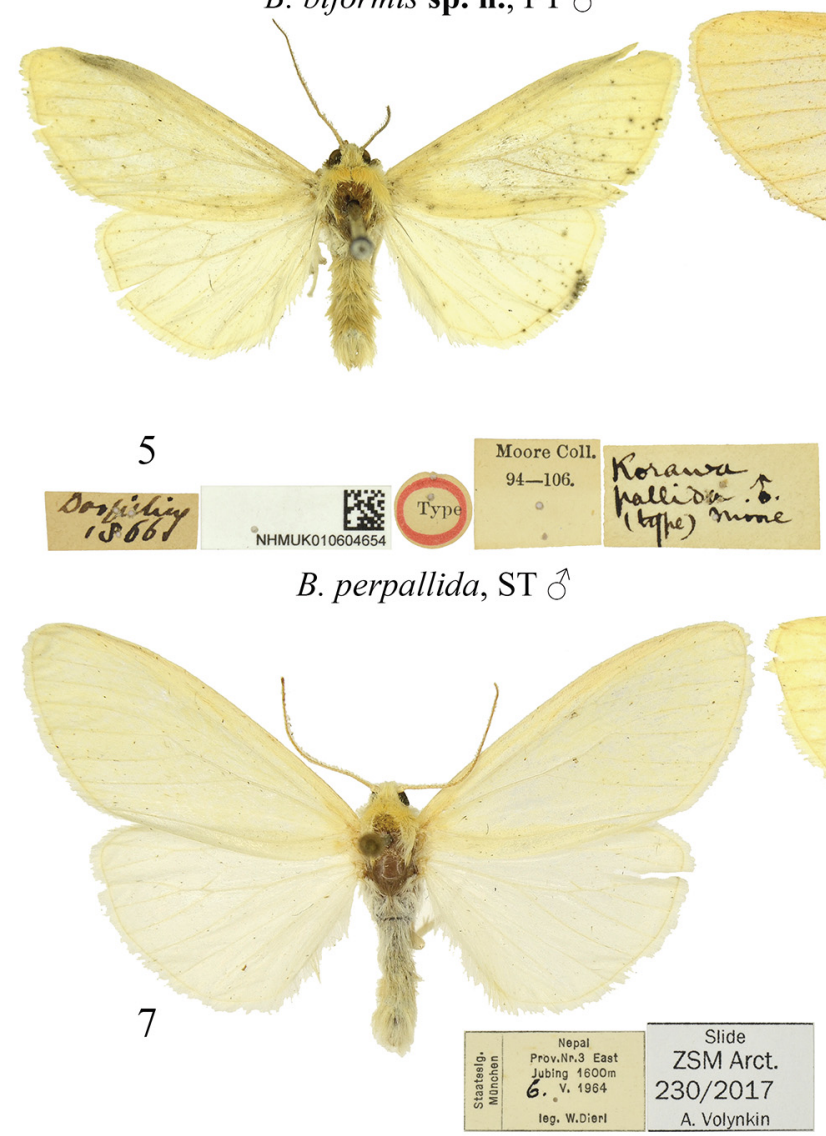

B. perpallida $\widehat{O}^{\lambda}$

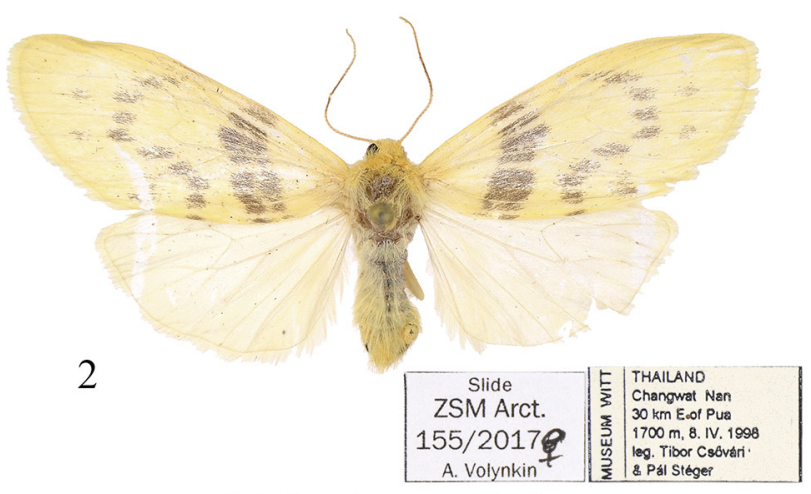

B. biformis sp. n., PT 우

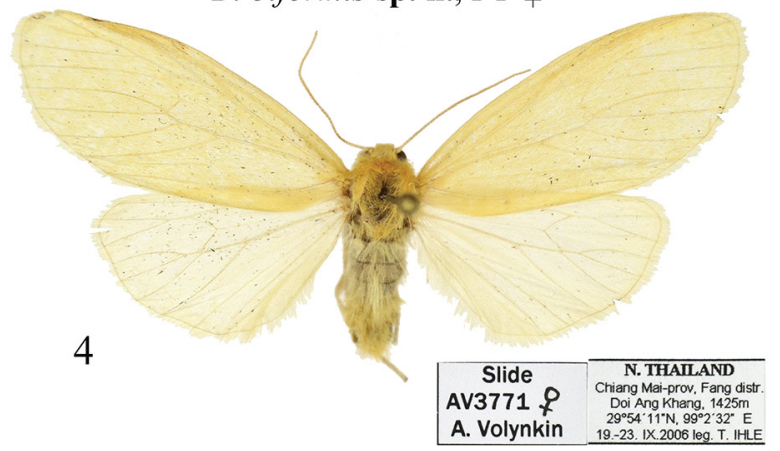

B. biformis sp. n., $\mathrm{PT}$ 우

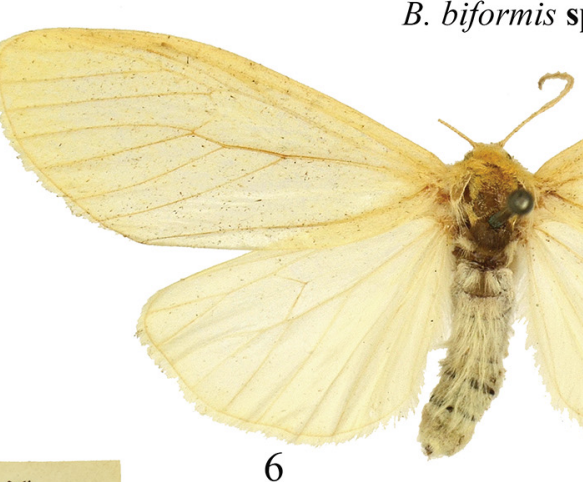

6

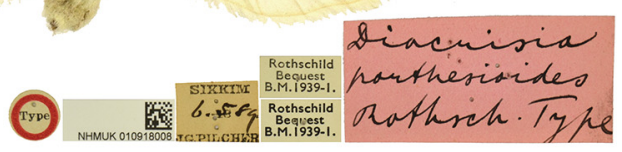

B. perpallida, ST $q$ of porthesioides
8

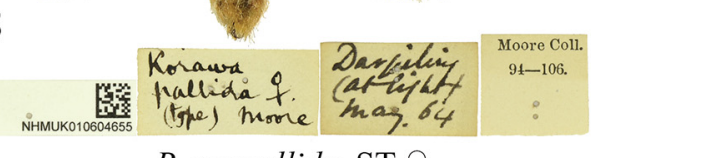

B. perpallida, $\mathrm{ST}$ q

$10 \mathrm{~mm}$

Figs 1-8. Barsine spp., adults. 1-4 - B. biformis sp. nov.: 1 - holotype $\widehat{\delta}$, Thailand (MWM/ZSM); 2 - paratype + , Thailand (MWM/ZSM); 3 - para-

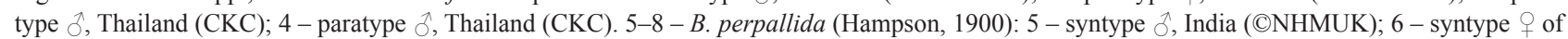
Diacrisia porthesioides Rothschild, 1910, India (CNHMUK); 7 - ô, Nepal (ZSM); 8 - syntype + , India (CNHMUK). 


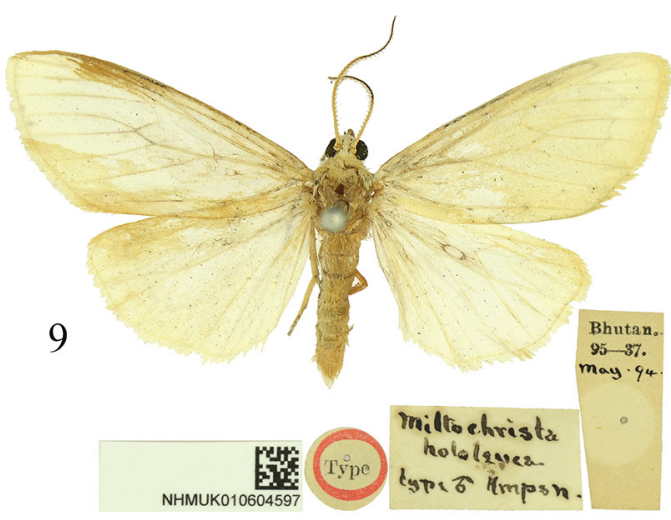

B. hololeuca, HT $\hat{\sigma}$

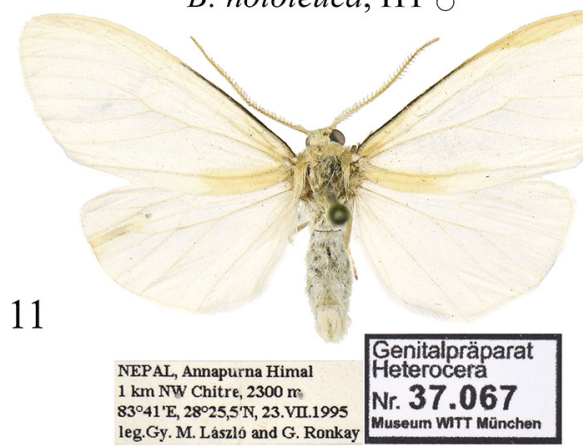

B. laszloi sp. n., HT $\partial$

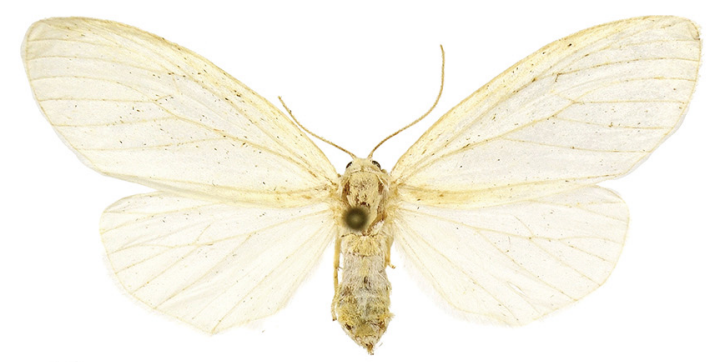

13

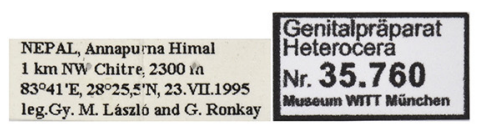

B. laszloi sp. n., PT +

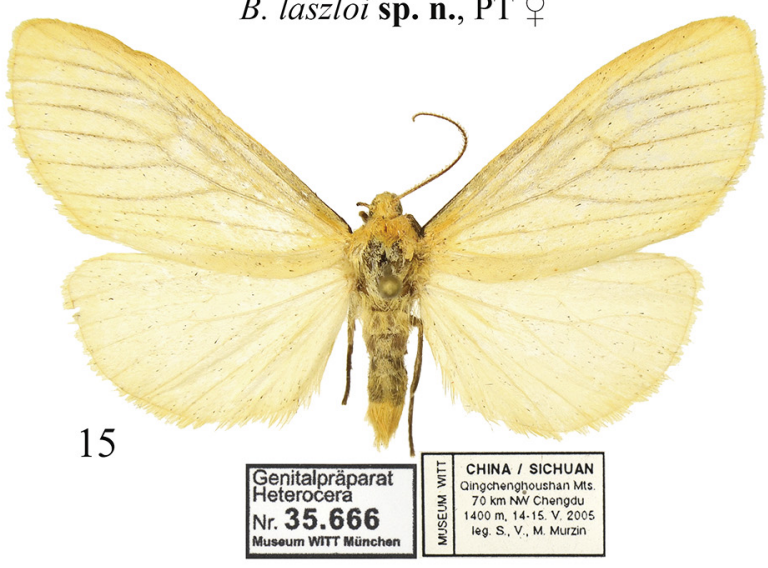

B. andromeda sp. n., PT $\precsim$

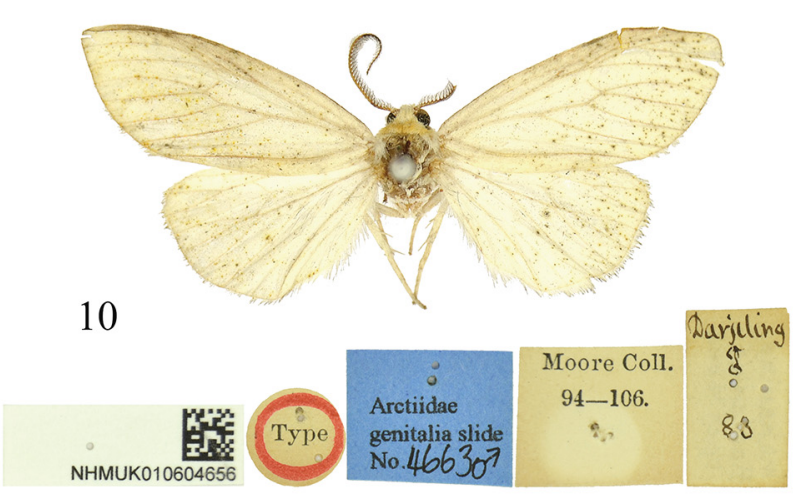

B. flavicollis, LT $\hat{\partial}$

12

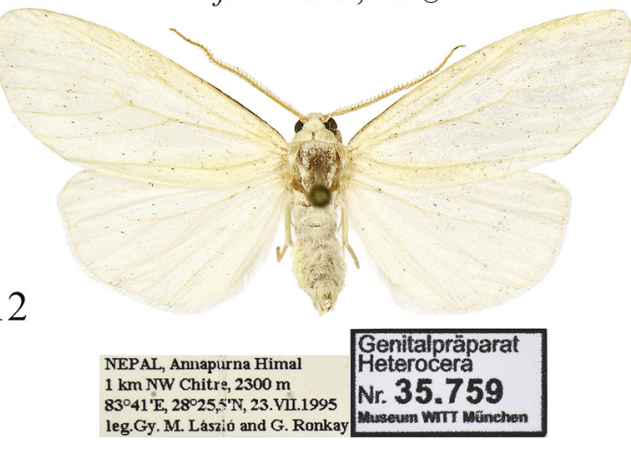

B. laszloi sp. n., PT $\widehat{\partial}$

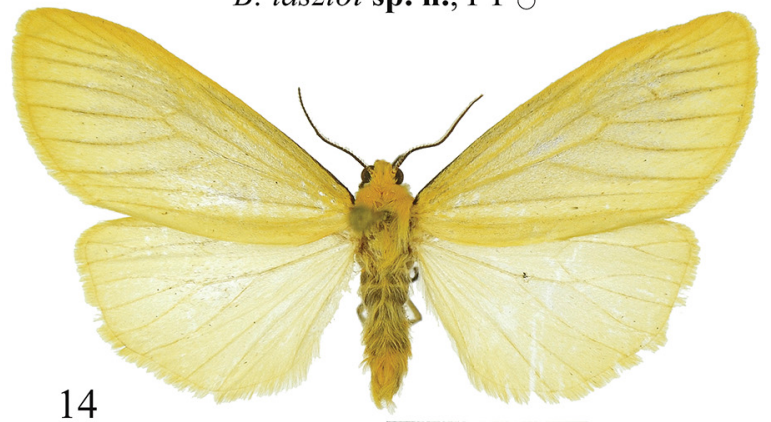

14

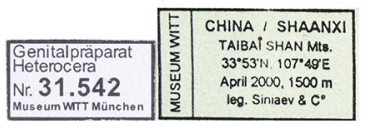

B. andromeda sp. n., HT ${ }^{\star}$

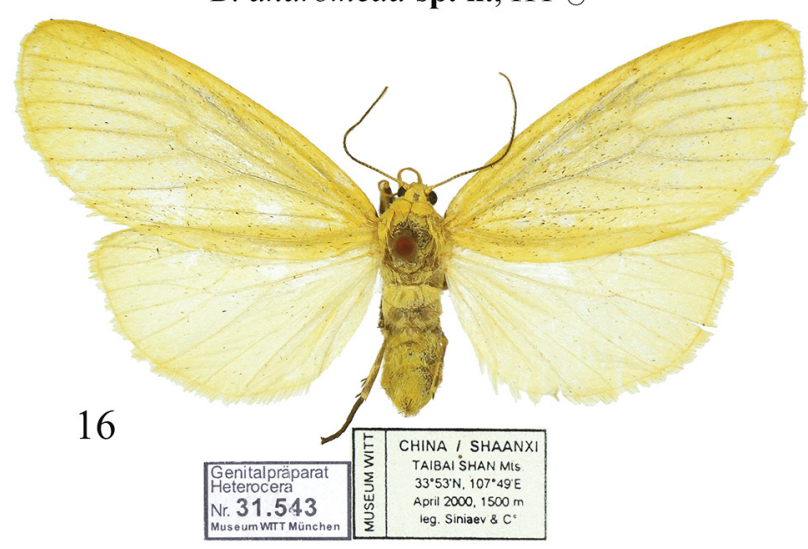

B. andromeda sp. n., PT $q$

Figs 9-16. Barsine spp., adults. 9 - B. hololeuca (Hampson, 1895), holotype $\widehat{O}$, Bhutan (CNHMUK); 10 - B. flavicollis (Moore, 1878), lectotype $\widehat{\delta}$, India (CNHMUK); 11-13 - B. laszloi sp. nov.: 11 - holotype ô, Nepal (MWM/ZSM); 12 - paratype ${ }^{2}$, Nepal (MWM/ZSM); 13 - paratype +, Nepal (MWM/ZSM); 14-16 - B. andromeda sp. nov.: 14 - holotype ${ }^{2}$, China (MWM/ZSM); 15 - paratype ${ }^{2}$, China (MWM/ZSM); 16 - paratype + , China (MWM/ZSM). 


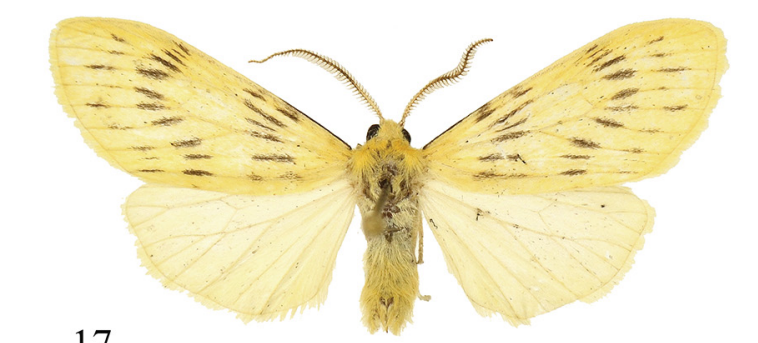

17

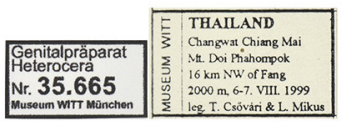

B. hausmanni sp. n., HT ठै

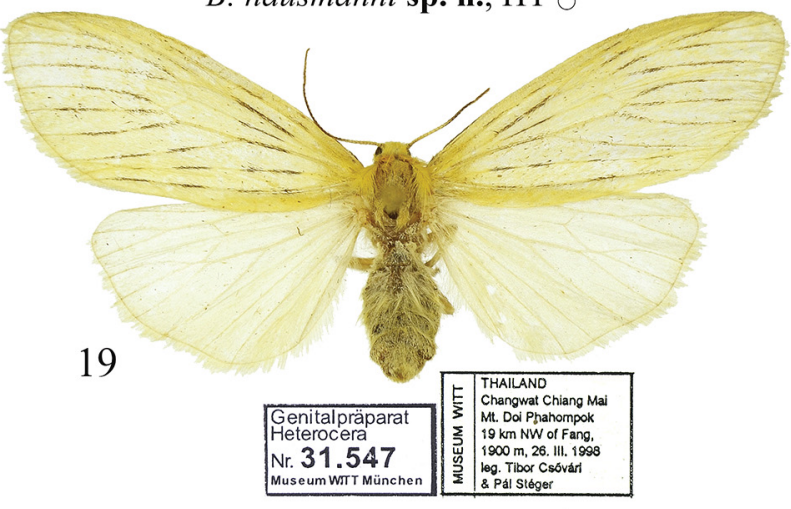

B. hausmanni sp. n., PT ?
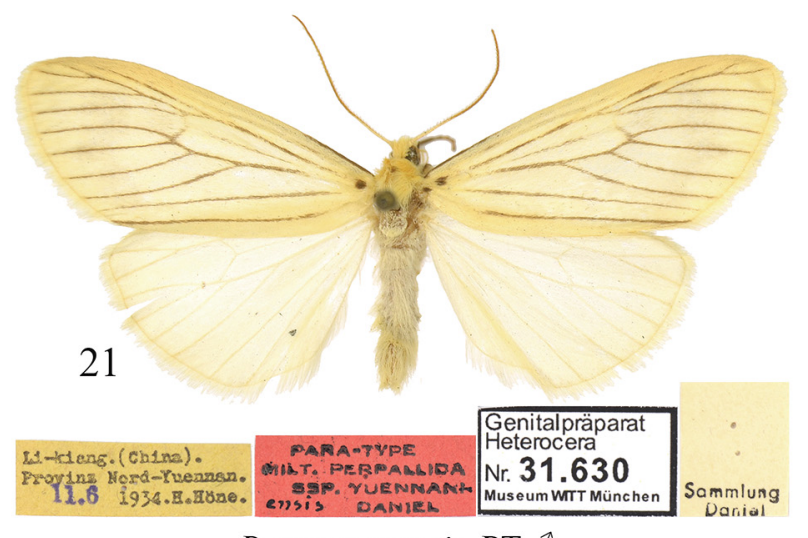

B. yuennanensis, PT के

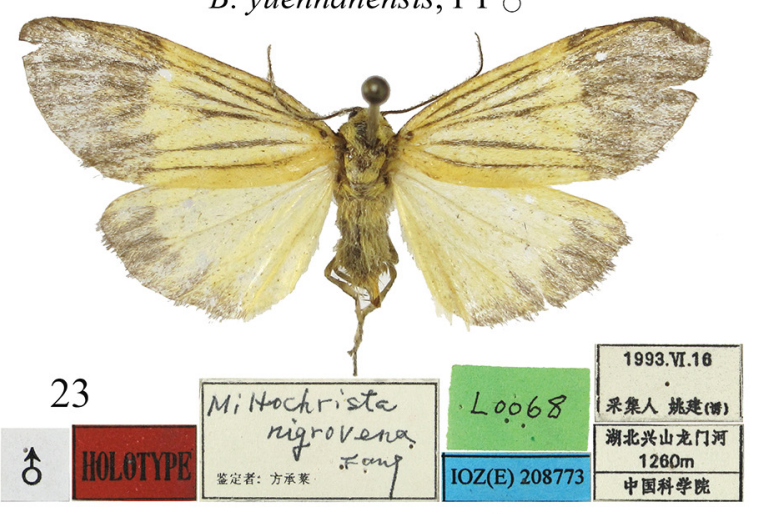

B. nigrovena, HT $\widehat{\partial}$
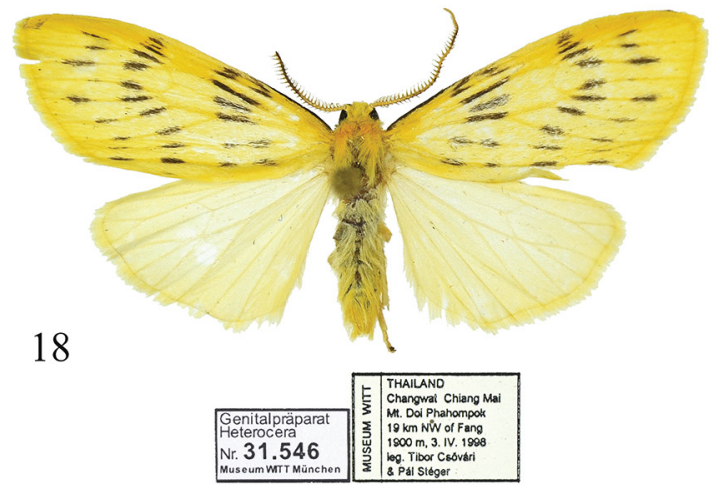

B. hausmanni sp. n., PT $\hat{~} \widehat{\partial}$

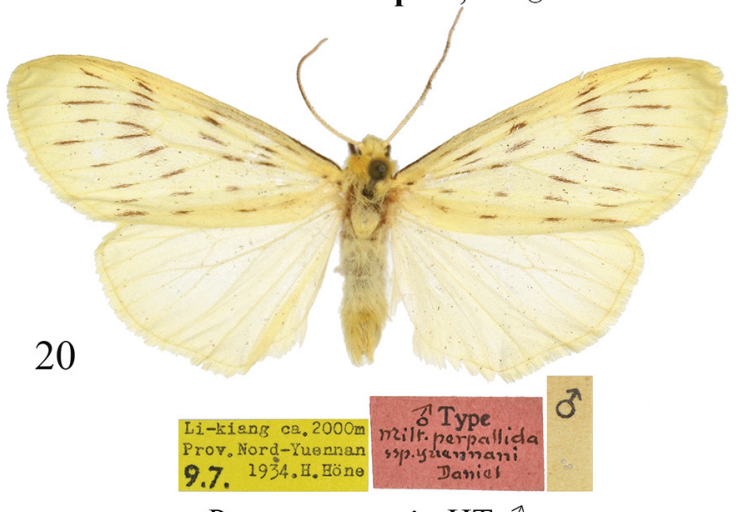

B. yuennanensis, HT बे
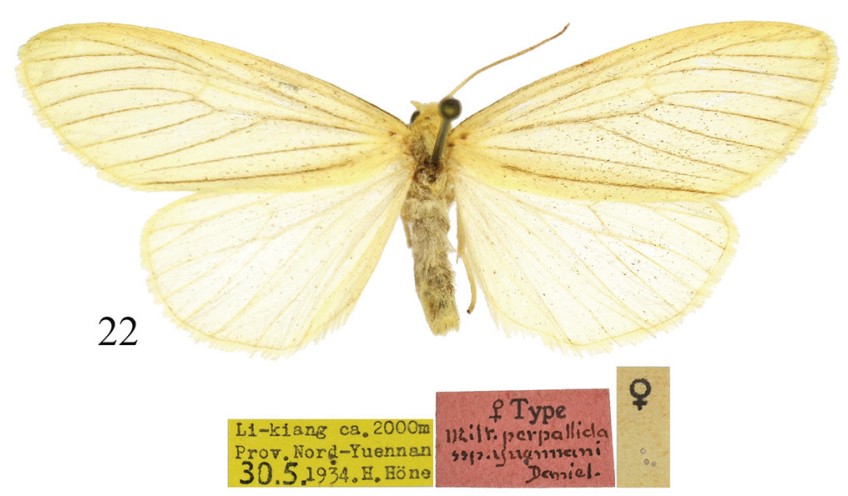

B. yuennanensis, PT 우

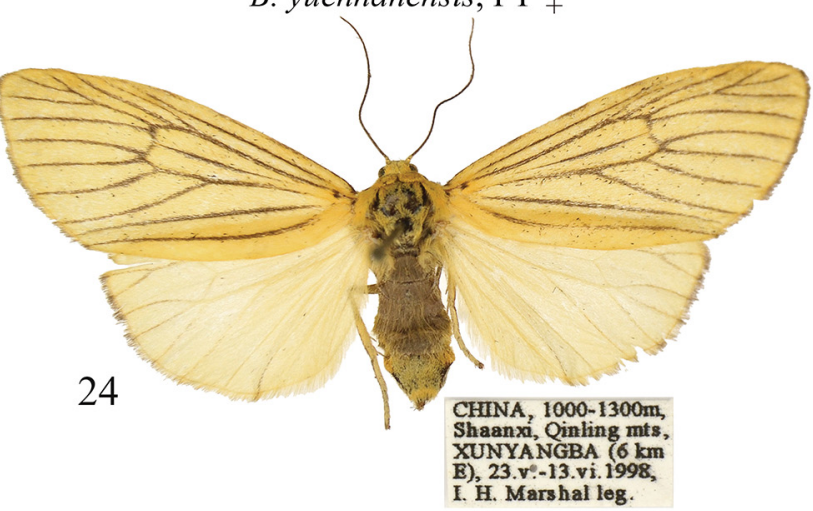

B. nigrovena 우

$10 \mathrm{~mm}$

Figs 17-24. Barsine spp., adults. 17-19- B. hausmanni sp. nov.: 17 - holotype ${ }^{2}$, Thailand (MWM/ZSM); 18 - paratype ${ }^{2}$, Thailand (MWM/ZSM); 19 - paratype + , Thailand (MWM/ZSM). 20-22 - B. yuennanensis (Daniel, 1952): 20 - holotype $\hat{\alpha}$, China, Yunnan (ZFMK); 21 - paratype $\hat{\rho}$, China, Yunnan (MWM/ZSM); 22 - paratype ${ }^{\text {, }}$, China, Yunnan (ZFMK). 23-24 - B. nigrovena (Fang, 2000): 23 - holotype $\$$, China, Hubei (ICZAS); $24-9$, China, Shaanxi (CKC). 


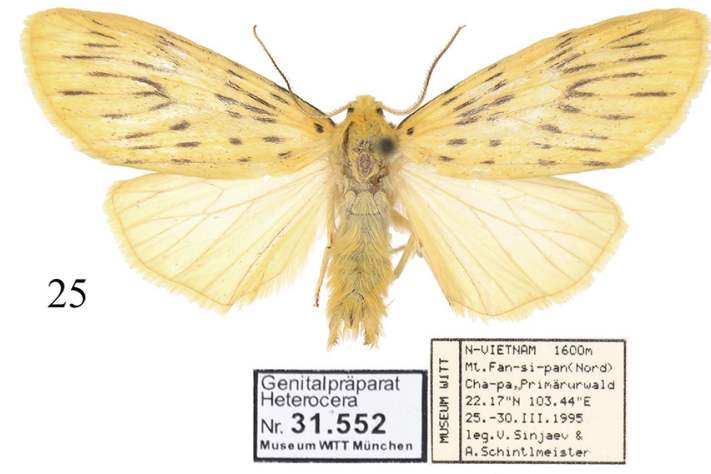

B. dao sp. n., HT $\delta$

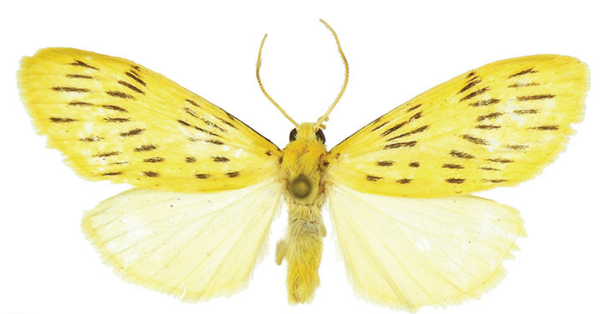

27

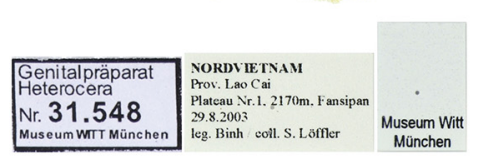

B. dao sp. n., PT ठ

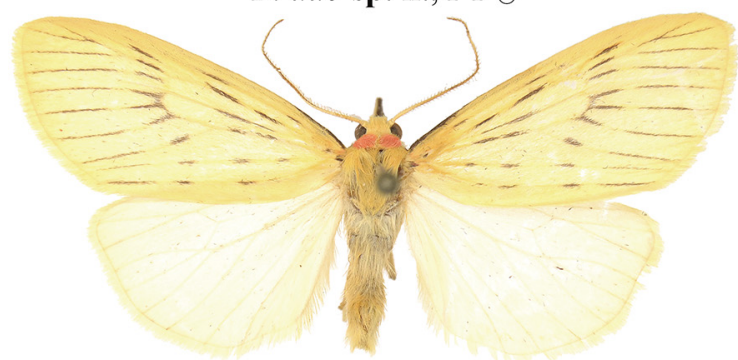

29

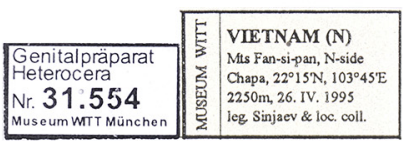

B. eurydice sp. n., HT ठ

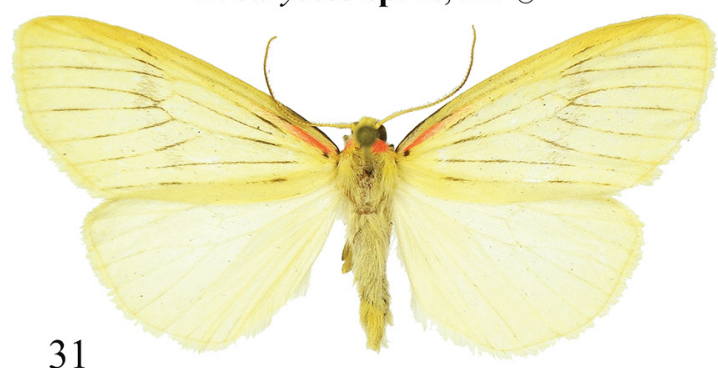

31

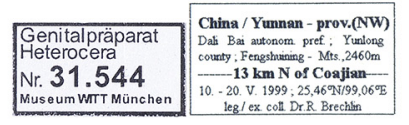

B. ruficollis §ै

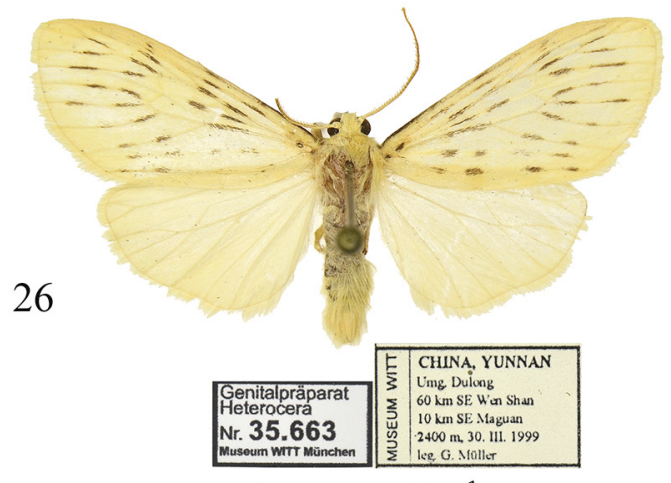

B. dao sp. n., PT $\jmath^{2}$

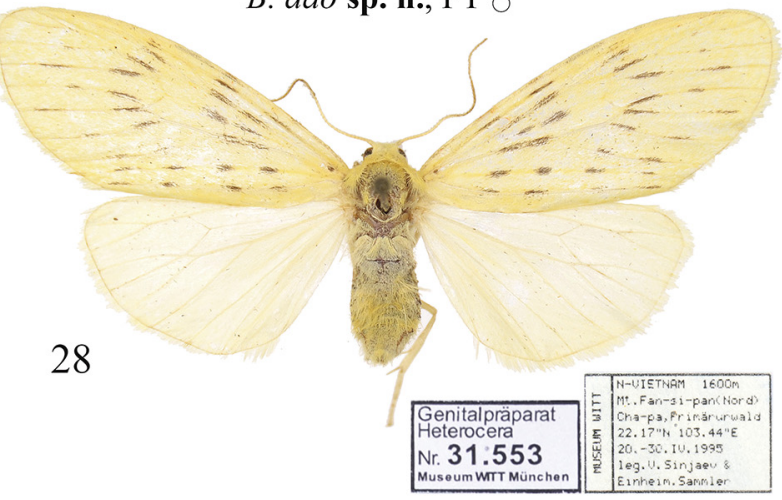

B. dao sp. n., PT 9

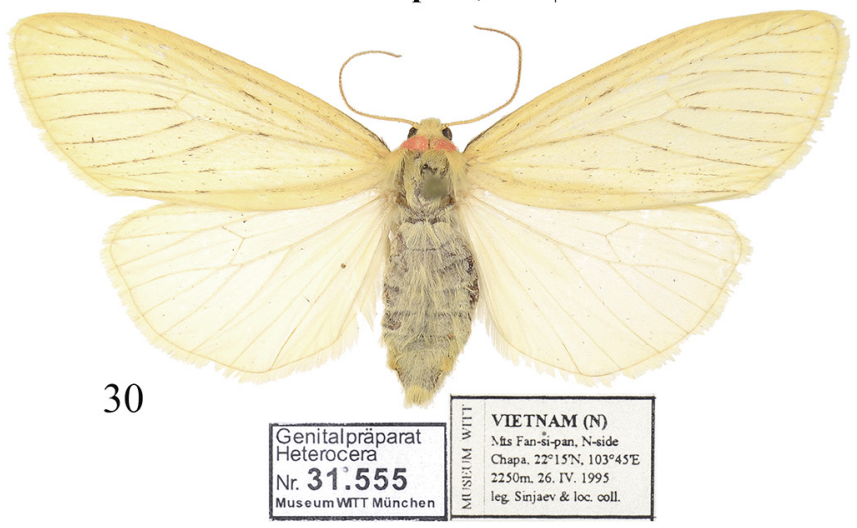

B. eurydice sp. n., HT $\hat{\sigma}$
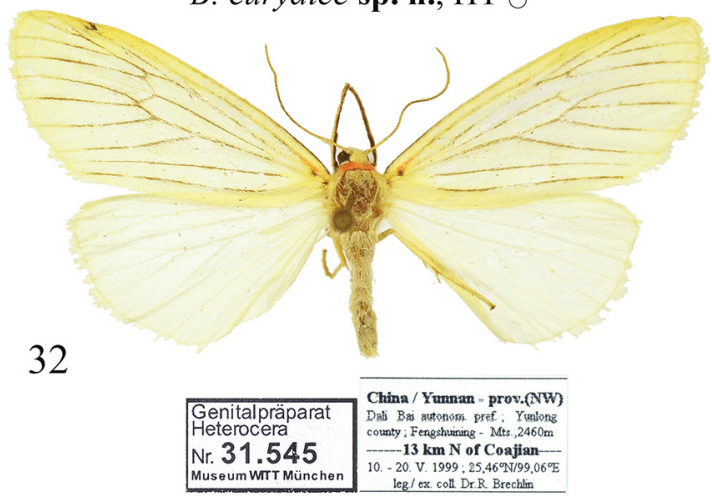

B. ruficollis + 
Swinhoe, 1891 (illustrated by VolYNKIN \& ČERNÝ 2016) and B. sieglindae Černý, 2016 (illustrated by ČERNÝ 2016), but $B$. biformis is well separated from them by its narrower juxta, the presence of a large, stick-like dentate subbasal process of valva costa, its smaller medial costal process, larger distal costal process, shorter basal saccular process, much stronger broadened distal saccular process with a longer and apically pointed dorsal lobe, and different configuration of diverticula of vesica. In the female genitalia, B. biformis (Fig. 48) differs from B. delicia (illustrated by VolynKIN \& ČERNÝ 2016) in its longer and narrower ductus bursae, stronger scobination of corpus bursae, the presence of the second signum, and shorter, conical and weaker sclerotized appendix bursae (in B. delicia, it is longer, heavily sclerotized and hook-like curved).

Description. Adult (Figs 1-4). Forewing length 14.0-15.0 $\mathrm{mm}$ in males (14.5 $\mathrm{mm}$ in holotype) and $18.5-19.0 \mathrm{~mm}$ in females. Male antennae ciliate, female antennae filiform. Body and forewing ochreous yellow. In patterned form, pattern dark grey, diffuse. Antemedial and medial lines consist of broad spots, often fused with each other. Postmedial line consists of wide longitudinal strokes of various length (those strokes interrupted in females). Hindwing pale yellow. Male genitalia (Fig. 33). Uncus narrow, its distal third curved, apically pointed; tuba analis membranous, subscaphium broad and setose; tegumen short and narrow; juxta weakly sclerotized, X-shaped; vinculum short, V-shaped. Valva broadened medially; basal part of costa broadened, with heavily sclerotized, long, stick-like dentate process directed distally. Medial costal process short, trigonal, with pointed apex; distal costal process well developed, trapezoidal. Distal membranous lobe of valva elongated, rounded apically, directed distally. Sacculus narrow, its basal process long, narrow, apically pointed, its distal half strongly curved dorsad. Distal saccular process strongly broadened, bilobate, its dorsal lobe directed dorsally, thorn-shaped; its distal process short, its apex blunt. Aedeagus straight, slightly narrowed medially. Vesica with membranous, elongated basal diverticulum and several medial diverticula. $1^{\text {st }}$ medial diverticulum bilobate, granulated, its larger lobe directed anteriorly; $2^{\text {nd }}$ medial diverticulum short, globular, with cluster of short thornlike cornuti; $3^{\text {rd }}$ medial diverticulum elongated, its distal half narrowed and apically rounded, granulated; $4^{\text {th }}$ medial diverticulum absent; $5^{\text {th }}$ medial diverticulum large, globular, with cluster of small but robust cornuti of various size. Basal plate of vesica ejaculatorius short, broad, trapezoidal. Female genitalia (Fig. 48). Papillae anales broad, trapezoidal with rounded corners, setose; apophyses long and thin, apophyses anteriores slightly shorter than apophyses posteriores. Ostium bursae broad. Ductus bursae elongated, dorso-ventrally flattened, sclerotized, its anterior half broadened, posterior half with several strong longitudinal subostial folds. Corpus bursae broad, sack-like, its medial and posterior sections dorsally with round sclerotized area surrounded by area of robust, shortly spinulose scobination. Large elliptical signum on ventral surface medially. Anterior section of corpus bursae membranous with smaller elliptical signum anteriorly.

Etymology. The species' name refers to the presence of two pattern forms within it. Adjective.
Distribution. The new species is known from North Thailand (Chiang Mai and Nan Provinces) (ČERNÝ \& PINRATANA 2009, as Korawa perpallida) and North Vietnam (Hòa Bình Province).

\section{Barsine perpallida subgroup}

Diagnosis. The subgroup is characterized by pale yellowish forewings without pattern, small juxta, distally broadened valva with a large distal costal process and unilobate distal saccular process, and the vesica structure: the $1^{\text {st }}$ medial diverticulum is strongly elongated and granulated, the $3^{\text {rd }}$ medial diverticulum is long and broad, the $6^{\text {th }}$ medial diverticulum is present, large.

\section{Barsine perpallida (Hampson, 1900)}

$$
\text { (Figs 5-7, 34, 35, 49) }
$$

Miltochrista perpallida Hampson, 1900: 495, pl. 32, fig. 22 (replacement name for Korawa pallida Moore, 1878).

= Korawa pallida Moore, 1878: 12 (original description). Type locality: "Darjiling" [= NE India, north of West Bengal, Darjeeling]). Junior secondary homonym of Calligena pallida Bremer, 1864, currently placed in Miltochrista.

= Diacrisia porthesioides Rothschild, 1910: 186 (original description). New junior subjective synonym. Type locality: [NE India], "Sikkim"

Type material examined. Korawa pallida. Syntypes (Figs 5, 6): 1 A, "Darjiling [Darjeeling] / 1866" (handwritten) // "Korawa / pallida / (type) Moore" (handwritten) // "Moore Coll. / 94-106" (printed) // round printed label with a red circle "Type" / printed label with QRcode "NHMUK010604654" (NHMUK); 1 + , "Darjiling [Darjeeling] / (at light) / May [18]64" (handwritten) // "Korawa / pallida $q$ / (type) Moore" (handwritten) // "Moore Coll. / 94-106" (printed) / printed label with QR-code "NHMUK010604655" (NHMUK); 1 \%, "Darjiling [Darjeeling] / 1864" (handwritten) // "coll. Atkinson" (printed) // "Coll. / Staudinger" (printed) (ZMB).

Diacrisia porthesioides: SyNTYPES (Figs 6, 49): 1 + , "Sikkim (printed) / 6.5.89 (handwritten) / J.G. Pilcher" (printed) // pink handwritten label "Diacrisia / porthesioides / Rothsch. Type" // printed label "Rothschild / Bequest / B.M. 1939-1." // printed label "Rothschild / Bequest / B.M. 1939-1." // round printed label with a red circle "Type" // printed label with QR-code "NHMUK010918008” (NHMUK); 1 +, "Sikkim (printed) / 29.4.89 (handwritten) / J.G. Pilcher" (printed) // printed label "Rothschild / Bequest / B.M. 1939-1." // printed label with QR-code "NHMUK010918009" (NHMUK); 1 \%, "Sikkim (printed) / 10.5.89 (handwritten) / J.G. Pilcher" (printed) // printed label "Rothschild / Bequest / B.M. 1939-1." // printed label with QR-code "NHMUK010918100", slide NHMUK010315755 Volynkin (NHMUK).

Other material examined. INDIA: West BENGAL: 1 , Darjeeling. July, 1886. H.J. Elwes. / Collectio H.J. Elwes / Rothschild Bequest B.M.1939-1. / NHMUK010604657, slide BMNH(E) Arct. 4665 (NHMUK); 2 웅, Darjeeling, Ex coll. Lidderdale (NHMUK); 1 \%, Darjeeling, 1864, slide BMNH(E) Arct. $4666 \precsim$ (NHMUK); 1 †, Darjeeling, 26.VIII.1886, H.J. Elwes (NHMUK); 1 , Darjeeling (at light) May [18]64 (NHMUK); 2 $\uparrow \circ$, Darjeeling, Dr. Lidderdale, 19-54 (NHMUK). NEPAL: 1 , Nepal, Prov. Nr. 3 East, Jubing, 1600 m, 6.v.1994, leg. W. Dierl, slide ZSM Arct. 230/2017 Volynkin(ZSM). CHINA: XIZANG: 1 1 1 , 24.v.2018, altitude $2450 \mathrm{~m}$, Cuona County, Shannan Prefecture, Tibet, leg. Tian-peng Chen, preparations in glycerol by Huang (SCAU).

Diagnosis. Forewing length is $16.0-19.5 \mathrm{~mm}$ in males and 21.0-22.5 $\mathrm{mm}$ in females. Externally, the species (Figs $5-7$ ) differs from the patternless form of $B$. biformis (Figs 3,4 ) in its larger size and paler forewing ground color; $B$. perpallida also resembles $B$. hololeuca and B. flavicollis, but differs from $B$. hololeuca (Fig. 8) in its pale ochreous patagia, slightly darker forewing ground color and ciliate 
male antennae (shortly bipectinate in B. hololeuca); from B. flavicollis (Fig. 9) it differs in its slightly darker forewing ground color and ciliate male antennae (shortly bipectinate in B. flavicollis). The male genitalia of B. perpallida (Figs 34, 35) differ from those of B. hololeuca (Fig. 36) and B. flavicollis (Fig. 37) in their smaller juxta, distally broadened valva with a large distal costal process, trigonal medial costal process directed distally, much longer basal saccular process, and different configuration of diverticula of vesica. The female genitalia of B. perpallida (Fig. 49)
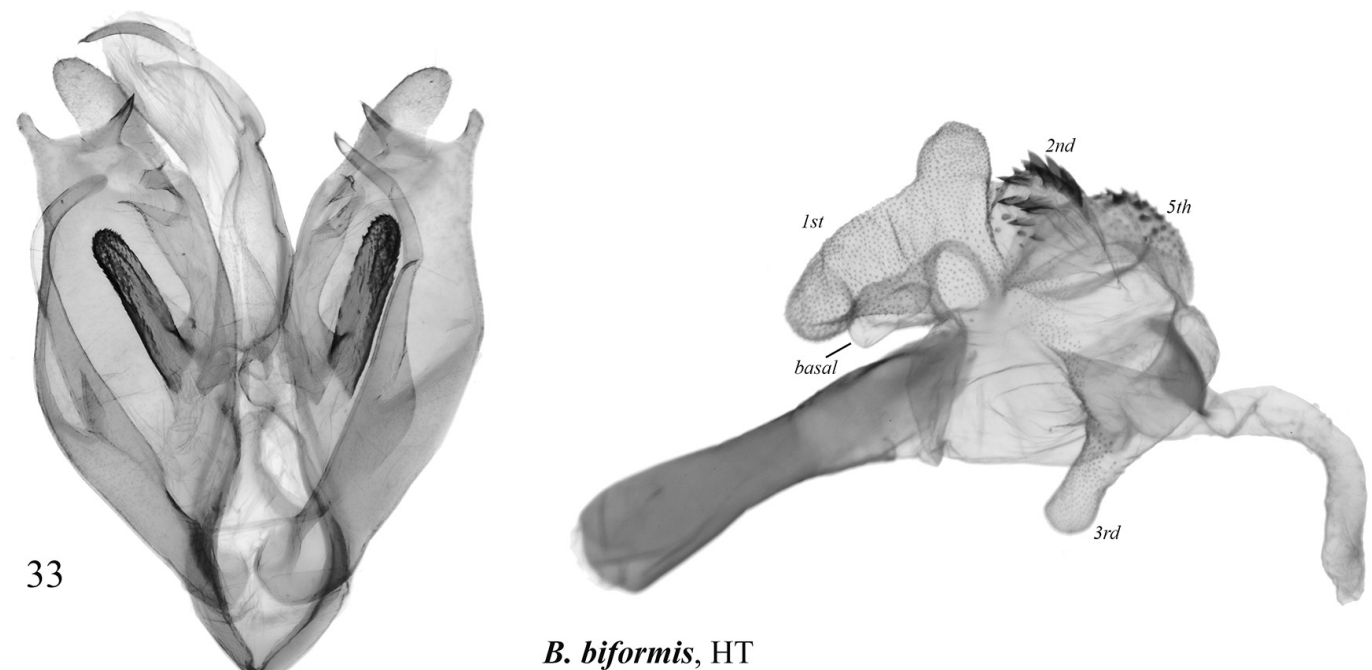

B. biformis, HT

N Thailand, Nan Prov., slide MWM 31351

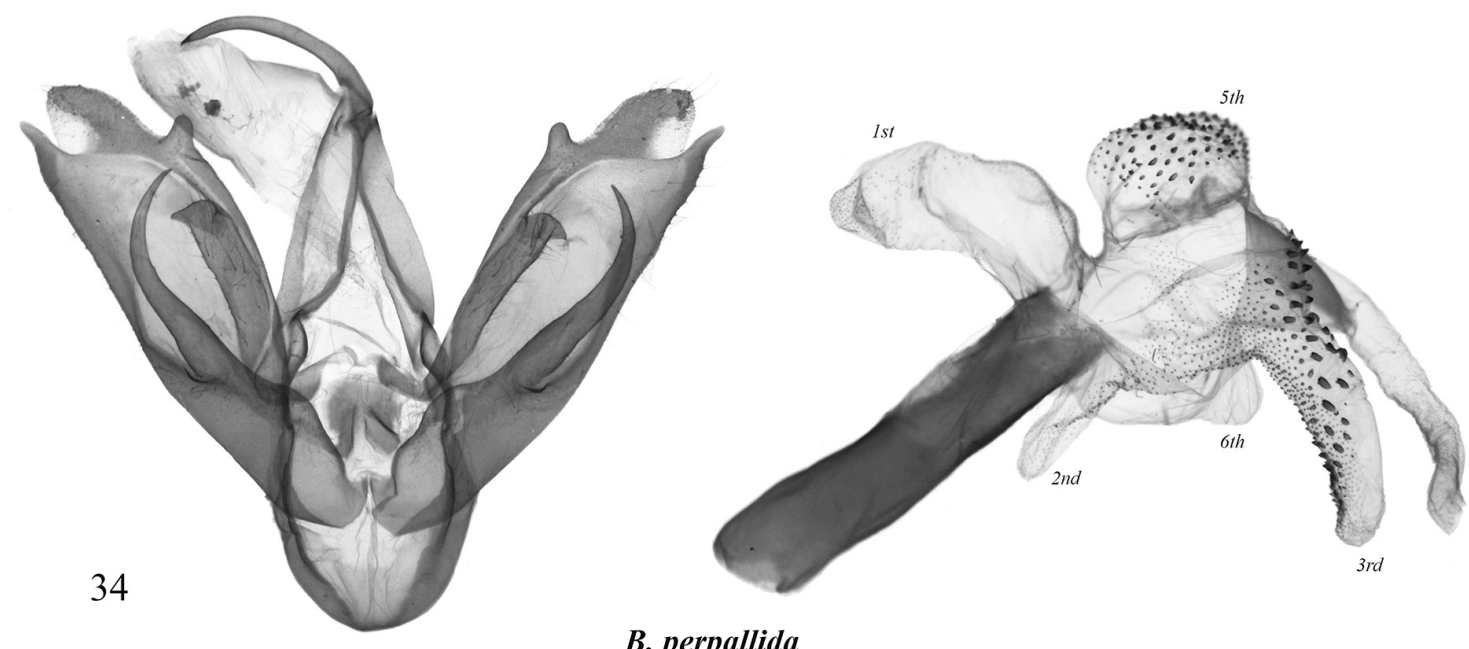

Nepal, Solukhumbu District, slide ZSM Arct. 230 / 2017
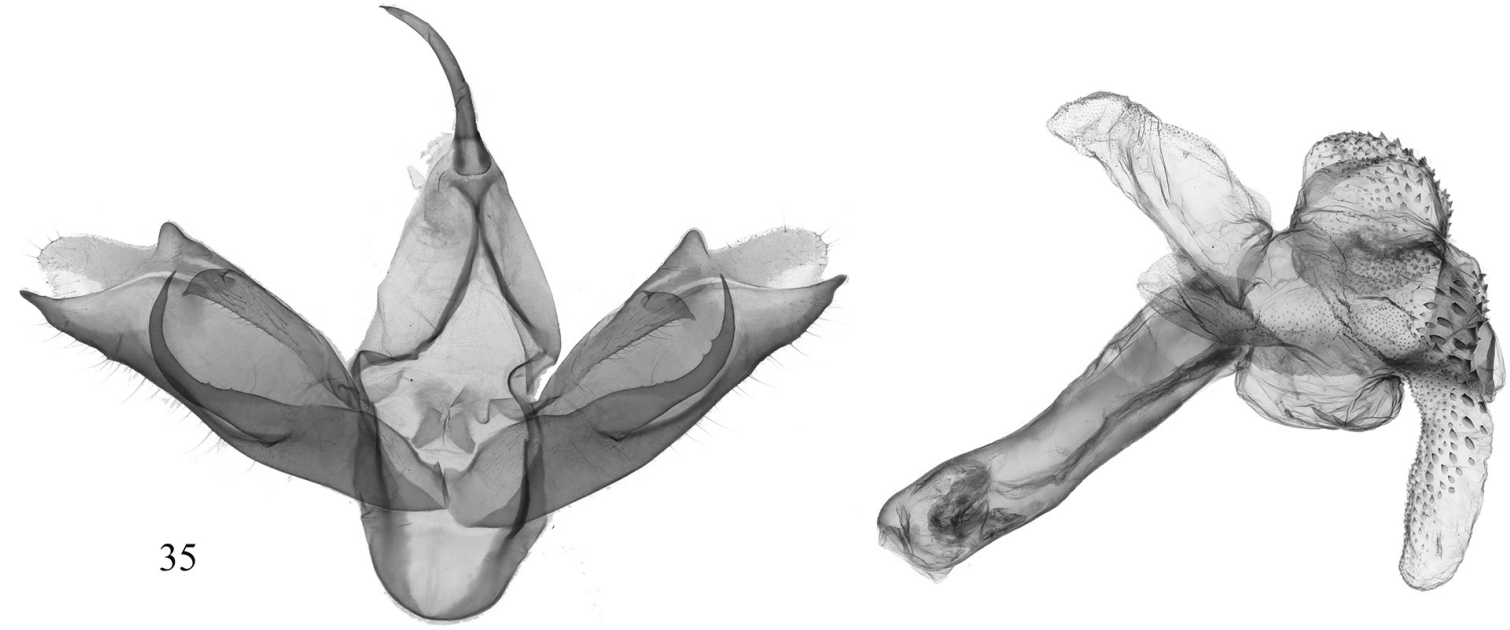

B. perpallida

China, Xizang, Shannan Prefecture, slide Huang

Figs 33-35. Barsine spp., male genitalia. 33 - B. biformis sp. nov., holotype, Thailand, slide MWM 31351 Volynkin. 34-35 - B. perpallida (Hampson, 1900): 34 - Nepal, slide ZSM Arct. 230/2017 Volynkin; 35 - China, Xizang, prep. Huang. 
differ from those of B. biformis (Fig. 48) in significantly narrower ductus bursae, smaller corpus bursae without signa and scobination, and longer appendix bursae.

Remarks. This species was considered by HAMPSON (1900) to be a member of the genus Miltochrista, and the name $M$. perpallida was introduced as a replacement for the name $M$. pallida Moore, 1878, which was a junior secondary homonym of Miltochrista pallida (Bremer, 1864). According to the article 59.3 of ICZN (1999), the name M. pallida Moore is permanently invalid as it was replaced before 1961 and the name $M$. perpallida was in use after its introduction (HAMPSON 1914; STRAND 1922; FANG 1991, 2000; Singh et al. 2014; ČERnÝ \& PinRatana 2009).

Diacrisia porthesioides was described on the base of female syntypes from Sikkim (RothsCHILD 1910). Examination of their genitalia proved their conspecificity with B. perpallida.

Distribution. North East India (Sikkim, north of West Bengal), East Nepal (Solukhumbu Distr.), China (Xizang). The records for Yunnan (FANG 1991, 2000) need confirmation.

\section{Barsine flavicollis subgroup}

Diagnosis. The subgroup is characterized by shortly bipectinate antennae in males, white forewing coloration without pattern (only the basal part of forewing costa is blackish), short basal saccular process, unilobate distal saccular process, and the vesica structure: the $1^{\text {st }}$ medial diverticulum is broad and membranous and the $2^{\text {nd }}$ medial diverticulum is narrow and weakly granulated.

\section{Barsine hololeuca (Hampson, 1895), comb. nov.} (Figs 8, 36)

Miltochrista hololeuca Hampson, 1895: 296. Type locality: "Bhután".

Type material examined. HоLотуре (by monotypy) (Figs 8, 36): $\hat{\jmath}$, "Bhutan. / 95-37. [printed] / May [18]94 [handwritten]" // "Miltochrista

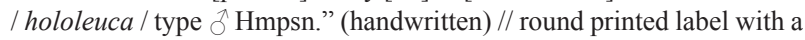
red circle "Type" / printed label with QR-code "NHMUK010604597", slide BMNH(E) Arct. 6580 of Volynkin (NHMUK).

Diagnosis. Forewing length is $16 \mathrm{~mm}$ in male. Externally, B. hololeuca (Fig. 8) differs from B. flavicollis (Fig. 9) in shorter lamellae of its antennae, white patagia (ochreous yellow in B. flavicollis), paler, white forewings, and shorter blackish basal area of forewing costa. Barsine hololeuca differs from B. laszloi (Figs 10-12) in its shorter blackish basal area of forewing costa and slightly more elongated forewing apex. In the male genitalia, B. hololeuca (Fig. 36) differs from B. flavicollis (Fig. 37) in its broader valva, slightly shorter and apically blunt medial costal process, shorter and broader, almost trigonal basal saccular process (narrow and elongated, blade-shaped in B. flavicollis), broader, shorter and less curved distal saccular process, larger $1^{\text {st }}$ medial diverticulum, and longer and distally narrower $3^{\text {rd }}$ medial diverticulum. The differences from $B$. laszloi are listed in the diagnosis of the latter.

Female is unknown.

Distribution. Barsine hololeuca is to date known only from the holotype collected in Bhutan (HAMPSON 1895). The record from China (Yunnan) (FANG 2000) needs confirmation.
Barsine flavicollis (Moore, 1878), comb. nov. (Figs 9, 37)

Mahavira flavicollis Moore, 1878: 11, pl. 1, fig. 3. Type locality: "Darjiling" [= NE India, north of West Bengal, Darjeeling].

Type material examined. Lестотуре (Figs 9, 37) (designated herein): o, "Darjiling / స/ 83" (handwritten) // "Moore Coll. / 94-106" (printed) // round printed label with a red circle "Type" / printed label with QRcode "NHMUK010604656" // blue label "Arctiidae genitalia slide No. (printed) 4663 '”" (handwritten) (NHMUK).

Diagnosis. Forewing length is $15.5 \mathrm{~mm}$ in male. Male of B. flavicollis (Fig. 9) can be distinguished from those of B. hololeuca (Fig. 8) and B. laszloi (Fig. 10) by its longer lamellae of antennae and pale ochreous patagia. In addition, in B. flavicollis the blackish basal area of forewing costa is longer than that of $B$. hololeuca. The male genitalia of $B$. flavicollis (fig. 37) differ from those of B. hololeuca (Fig. 36 ) in narrower valva; slightly longer medial costal process with claw-shaped tip; longer and narrower, blade-shaped basal saccular process (almost trigonal, short and broad in $B$. hololeuca); narrower, longer and more strongly curved distal saccular process; smaller $1^{\text {st }}$ medial diverticulum; and slightly shorter and distally broader $3^{\text {rd }}$ medial diverticulum. The differences from B. laszloi are listed in the diagnosis of the latter species.

Female is unknown.

Distribution. North East India (north of West Bengal) (Moore 1878).

Remarks. HAMPSON (1900) incorrectly cited the holotype label as "Sikhim", while it is "Darjiling" (Moore 1878).

In the NHMUK collection, there is only one male syntype of B. flavicollis, which we designate here as lectotype. Other, non-type specimens placed in the NHMUK collection under the name B. flavicollis belong to Macrobrochis pallens (Hampson, 1894).

\section{Barsine laszloi Volynkin \& Černý, sp. nov.} (Figs 10-12, 38, 50)

Type locality. Nepal, Annapurna Himal, 1 km NW Chitre, 2300 m, $83^{\circ} 41^{\prime} \mathrm{E} 28^{\circ} 25.5^{\prime} \mathrm{N}$.

Type material. HolotyPe (Figs 10, 38): 3 , "Nepal, Annapurna Himal /

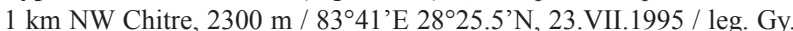
M. László and G. Ronkay", slide MWM 37067 Volynkin (MWM/ZSM). PARATYPES: 41 , same data as in the holotype, slides MWM 35759 (ठ), MWM 35760 (†) Volynkin (MWM/ZSM).

Diagnosis. The new species is the closest relative of $B$. flavicollis. Externally these two species are very similar (Figs 9-12), but B. laszloi can be distinguished by shorter lamellae of male antennae and white patagia (pale ochreous in B. flavicollis). In the male genitalia, B. laszloi (Fig. 38) differs from B. flavicollis (Fig. 37) in its smaller juxta, broader tip of medial costal process (claw-like pointed in B. flavicollis), shorter basal saccular process, broader distal saccular process, longer and narrower $1^{\text {st }}$ medial diverticulum, longer and basally granulated $2^{\text {nd }}$ medial diverticulum (membranous in B. flavicollis), much longer $3^{\text {rd }}$ medial diverticulum with more numerous cornuti, and smaller $5^{\text {th }}$ medial diverticulum. The male genitalia of $B$. laszloi differ from those of $B$. hololeuca (Fig. 36) in their narrower valva, longer and narrower basal saccular process, their longer and slightly narrower 
distal saccular process, broader $1^{\text {st }}$ medial diverticulum, stronger cornuti on $3^{\text {rd }}$ medial diverticulum, narrower base of the $3^{\text {rd }}$ medial diverticulum, and the presence of only granulation at base of the $3^{\text {rd }}$ medial diverticulum (in $B$. hololeuca there is a broad cluster of short robust cornuti at base of the $3^{\text {rd }}$ medial diverticulum). The females of $B$. flavicollis and $B$. hololeuca are unknown therefore the female genitalia of B. laszloi (Fig. 50) can be compared only with the externally similar, but not closely related species B. perpallida (Fig. 49), from which B. laszloi
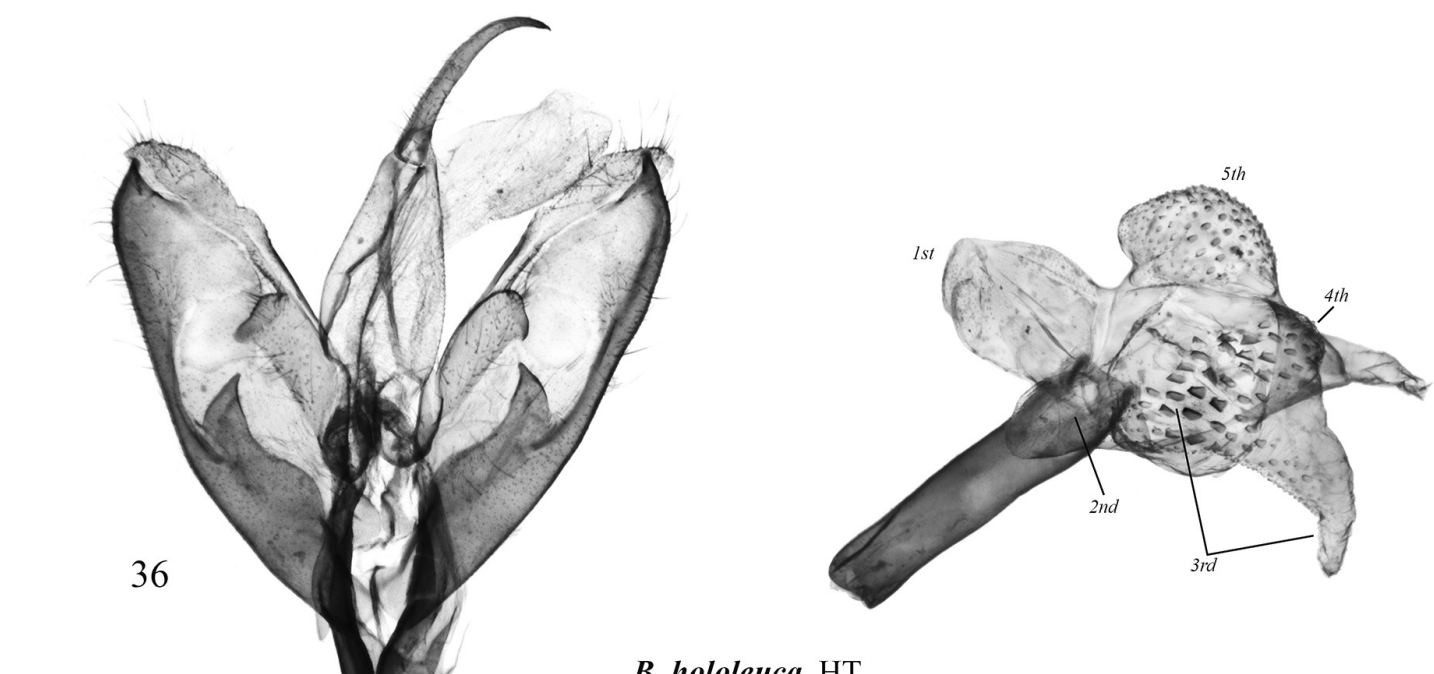

B. hololeuca, HT

Bhutan, slide BMNH(E) Arct-6580

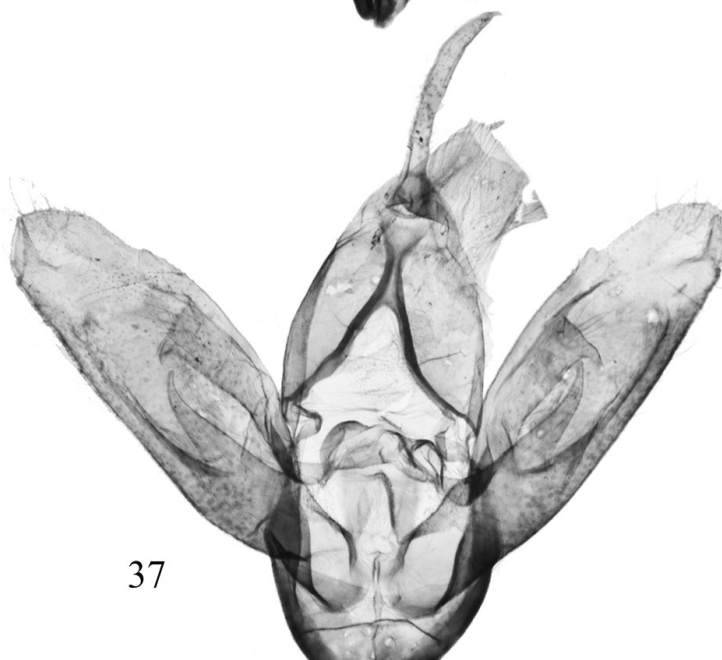

B. flavicollis, LT
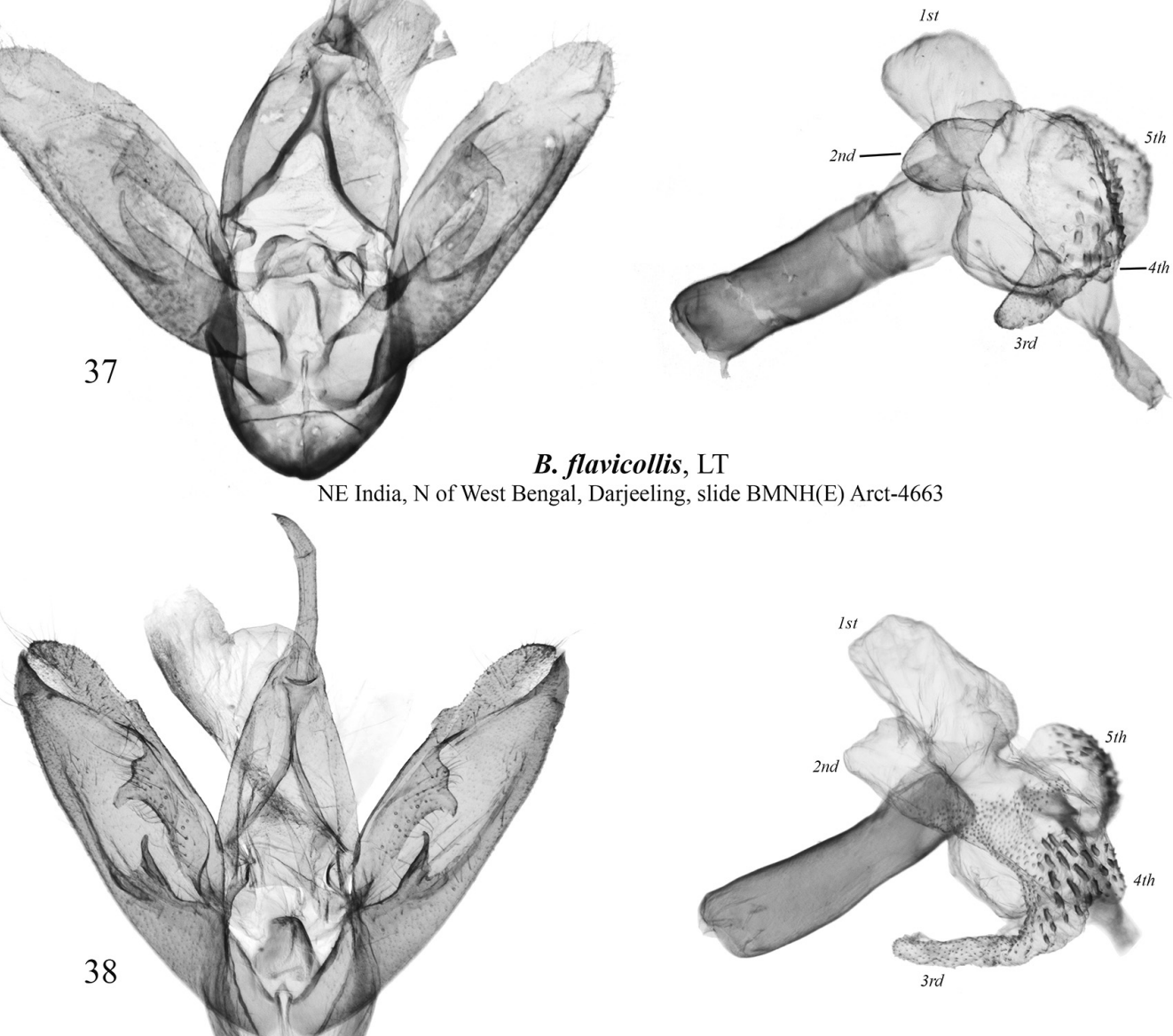

B. laszloi sp. n., HT

Central Nepal, Annapurna Himal, slide MWM 37067

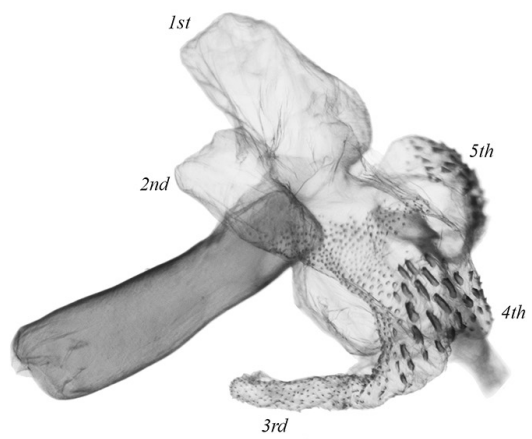

Figs 36-38. Barsine spp., male genitalia. 36 - B. hololeuca (Hampson, 1895), holotype, Bhutan, slide BMNH(E) Arct-6580 Volynkin (CNHMUK). 37 - B. flavicollis (Moore, 1878), lectotype, India, slide BMNH(E) Arct-4663 (CNHMUK). 38 - B. laszloi sp. nov., holotype 3 , Nepal, slide MWM 37067 Volynkin. 
differs in slightly broader and much shorter ductus bursae with shorter longitudinal subostial folds, and the presence of shortly spinulose scobination in the medial section of corpus bursae.

Description. Adult (Figs 10-12). Forewing length is $15.0-15.5 \mathrm{~mm}$ in males (15.5 $\mathrm{mm}$ in holotype) and 17.0 $\mathrm{mm}$ in female. Male antennae shortly bipectinate, female antennae filiform. Body and ground color of both wings pure white. Basal half of forewing costa blackish. Male genitalia (Fig. 38). Uncus narrow, laterally flattened, dorso-ventrally curved, apically pointed. Tuba analis broad, membranous, subscaphium broad and setose. Tegumen moderately broad, shorter than valva. Juxta short, X-shaped, with short medial dorsal protrusion. Vinculum short, U-like. Valva elongated, slightly narrowed distally. Medial costal process short, apically blunt, its outer margin curved. Distal costal process short, tubercle-like. Distal membranous lobe of valva moderately broad, elongated, apically rounded, directed distally. Sacculus broad basally and strongly narrowed medially and distally, its basal process short, narrowly trigonal, slightly curved dorsally. Distal saccular process short, broadly trigonal with blunt apex, reaches the valva apex. Aedeagus straight, moderately broad. Medial section of vesica with area of weak granulation at base of $3^{\text {rd }}$ medial diverticulum; $1^{\text {st }}$ medial diverticulum of vesica broad, globular, membranous; $2^{\text {nd }}$ medial diverticulum narrow, elongated, finger-shaped, weakly granulated; $3^{\text {rd }}$ medial diverticulum elongated, covered with numerous short but robust cornuti of various size; $4^{\text {th }}$ medial diverticulum short, broad, covered with small short cornuti; $5^{\text {th }}$ medial diverticulum broad, globular, its outer surface with cluster of numerous short but robust cornuti of various size. Basal plate of vesica ejaculatorius narrow, elliptical. Female genitalia (Fig. 50). Papillae anales broad, trapezoidal with rounded corners, setose. Apophyses long and thin, apophyses anteriores slightly shorter than apophyses posteriores. Ostium bursae broad. Ductus bursae broad, short, dorso-ventrally flattened, its posterior half with several narrow longitudinal subostial folds. Corpus bursae ovoid, its anterior third membranous; posterior section of corpus bursae weakly sclerotized; medial section of corpus bursae weakly sclerotized, with weak, shortly spinulose scobination and one small, narrow signum. Appendix bursae large, moderately sclerotized, situated postero-laterally, its base broad, its distal section elongated, narrowly conical.

Etymology. The species is dedicated to Dr. Gyula M. László (Leominster, UK), the collector of the type series and the senior author's friend.

Distribution. Barsine laszloi is to date known only from its type locality, Annapurna mountain massif in northern Central Nepal.

\section{Barsine hausmanni subgroup}

Diagnosis. The single known species of the subgroup is externally similar to members of the $B$. yuennanensis subgroup, but is characterized by bipectinate antennae of males (ciliate in the B. yuennanensis subgroup), narrow trigonal medial saccular process directed ventrally-distally (in the B. yuennanensis subgroup it is broader and directed more or less ventrally), and unilobate distal saccular process (bilobate in the B. yuennanensis subgroup).

\section{Barsine hausmanni Volynkin \& Černý, sp. nov.} (Figs 17-19, 39, 51)

Barsine yuennanensis (misidentification): ČERNÝ \& PINRATANA (2009): 70, pl. 15, fig. 139 (record from Thailand).

Type locality. Thailand, Changwat Chiang Mai, Mt. Doi Phahompok, $16 \mathrm{~km}$ NW of Fang, ca. $20^{\circ} 4^{\prime} \mathrm{N} 99^{\circ} 8^{\prime} \mathrm{E}, 2000 \mathrm{~m}$.

Type material. HоLотуре (Figs 17, 39): $\hat{\jmath}$, “Thailand / Changwat Chiang Mai / Mt. Doi Phahompok / 16 km NW of Fang / 2000 m, 6-7.VIII.1999 / leg. T. Csővári \& L. Mikus", slide MWM 35665 Volynkin (MWM/ ZSM). PARATYPES: 30 우, same data as in the holotype, slides MWM 31537 (m), ZSM Arct. 148/2017우 Volynkin (MWM/ZSM); 2 唡 1 ㅇ, Thailand, Changwat Chiang Mai, Mt. Doi Phahompok, $19 \mathrm{~km} \mathrm{NW}$ of Fang, 1900 m, 3.iv.1998, leg. Tibor Csővári \& Pál Stéger, slide MWM 31546 ( ), MWM 31547 () Volynkin (MWM/ZSM); 5 우 2 우, N Thailand, Chiang Mai, Fang, Doi Pha Hom Pok, 2050m, $20^{\circ} 07^{\prime} 30^{\prime \prime} \mathrm{N}$,

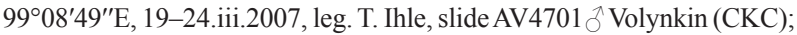
$1 \delta 1$, same locality and collector, but 21-25.viii.2006 (CKC); 1 , same locality and collector, but 27-31.x.2006 (CKC).

Diagnosis. Barsine hausmanni (Figs 17-19) is very similar externally to B. yuennanensis (Figs 21-24) and B. dao (Figs 25-28), but differs in bipectinate antennae in males (ciliate in B. yuennanensis and B. dao). In addition, in $B$. hausmanni the dashes of the subterminal area are usually slightly shorter than those of $B$. dao. Barsine hausmanni also differs from B. yuennanensis in its darker coloration, slightly longer and broader dashes of transverse lines, and the antemedial and medial lines connected in the cell. The male genital capsule of B. hausmanni (Fig. 39) can be easily distinguished from those of $B$. yuennanensis (Figs 42, 43) and B. dao (Figs 46, 47) by unilobate distal saccular process, shorter valva, and narrower and trigonal medial saccular process directed ventrally-distally (in $B$. yuennanensis it is broader, while in $B$. dao it is broader and has a strongly narrowed tip directed ventrally). The vesica shape of $B$. hausmanni is significantly different from those of $B$. yuennanensis and $B$. dao in its broad and membranous $1^{\text {st }}$ medial diverticulum (narrow and hook-like curved in B. yuennanensis, and small, globular and granulated in $B$. dao), shorter and broader $2^{\text {nd }}$ medial diverticulum (elongated, narrowed, with a basal subdiverticulum in B. yuennanensis, and elongated and broadly conical in $B$. dao), elongated and narrow distal section of the $3^{\text {rd }}$ medial diverticulum (short and broad in B. yuennanensis and $B$. dao), membranous $4^{\text {th }}$ diverticulum (with clusters of short but robust cornuti in B. yuennanensis and $B$. dao); in addition, the $5^{\text {th }}$ diverticulum has a cluster of cornuti occupying only half of its outer surface, while in $B$. yuennanensis and $B$. dao $5^{\text {th }}$ diverticula are evenly covered by cornuti. The female genitalia of $B$. hausman$n i$ (Fig. 51) differ from those of B. yuennanensis (Fig. 53 ) in shorter apophyses anteriores, slightly longer and much broader ductus bursae, broader corpus bursae with broader sclerotized and scobinated posterior area having two signa (in B. yuennanensis there is one signum), and larger appendix bursae. Compared to those of $B$. dao (Fig. 56 ), the female genitalia of $B$. hausmanni have shorter 
apophyses anteriores, round ostium bursae (while it has a horseshoe-shaped concavity in $B$. dao), ductus bursae stronger broadened anteriorly (only slightly broadened anteriorly in $B$. dao), less rugose posterior sclerotized section of corpus bursae, membranous anterior section of corpus bursae (in $B$. dao it is weakly sclerotized and rugose laterally), and the presence of two signa in the posterior section of corpus bursae (while in B. dao there are one signum in the posterior section and one signum in the anterior section of corpus bursae).

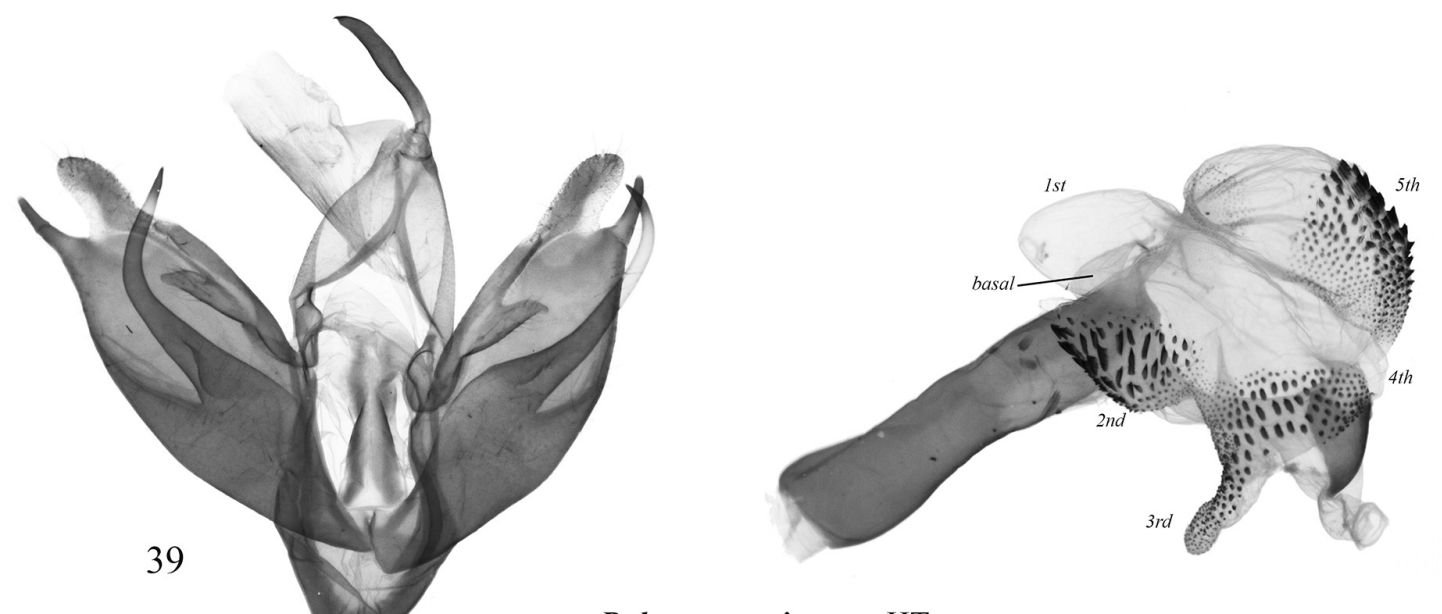

B. hausmanni sp. n., HT

N Thailand, Chiang Mai Prov., Doi Phahompok Mts, slide MWM 35665

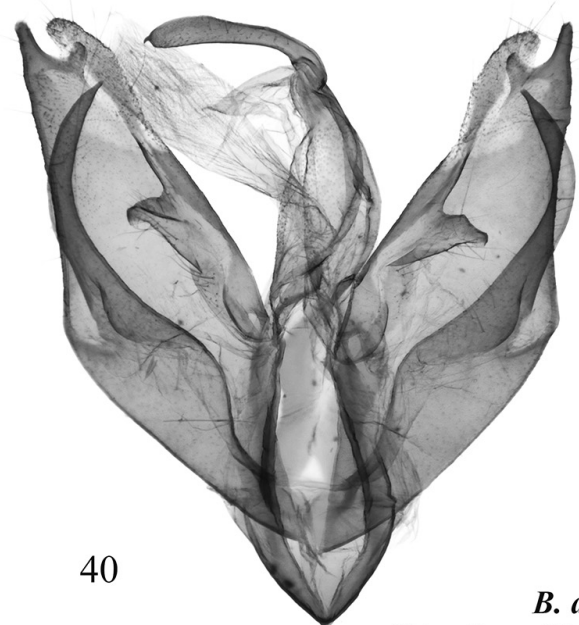

B. andromeda sp. n., HT

China, Shaanxi Prov., Taibai Shan Mts, slide MWM 31542

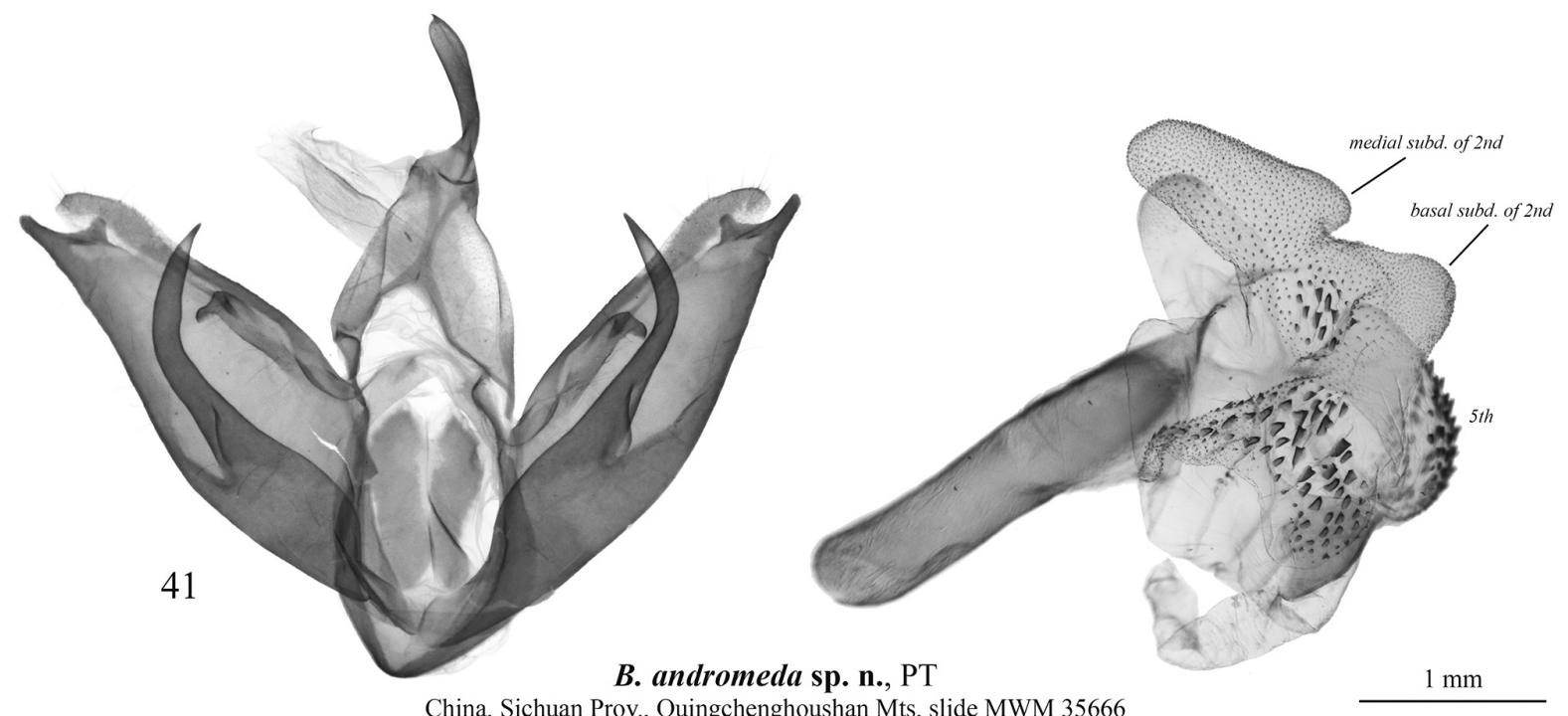

Figs 39-41. Barsine spp., male genitalia. 39 - B. hausmanni sp. nov., holotype ổ, Thailand, slide MWM 35665 Volynkin. 40-41 - B. andromeda sp. nov.: 40 - holotype, China, slide MWM 31542 Volynkin; 41 - paratype, China, slide MWM 35666 Volynkin. 
Description. Adult (Figs 17-19). Forewing length is $16.0-17.0 \mathrm{~mm}$ in males (16.0 $\mathrm{mm}$ in holotype) and $19.0-19.5 \mathrm{~mm}$ in females. Male antennae bipectinate, female antennae ciliate. Head and thorax from ochreous yellow to bright yellow; abdomen pale ochreous basally and ochreous yellow or bright yellow distally. Forewing ground color from ochreous yellow to bright yellow. Pattern black. Antemedial and medial lines slightly curved, consist of elongated dashes on veins, situated closely to each other, sometimes their dashes connected in the cell; postmedial line curved, consist of elongated dashes on veins; subterminal area with series of longitudinal dashes of various length on veins. In females pattern more diffuse, longitudinal dashes thinner and often fused to each other. Cilia as forewing ground color. Hindwing pale yellow. Male genitalia (Fig. 39). Uncus narrow, elongated, slightly wavy medially, claw-like pointed apically. Tuba analis broad, membranous, subscaphium broad and setose. Tegumen short and narrow. Juxta long and narrow, X-shaped. Vinculum short, U-shaped. Valva broadened medially and strongly narrowed distally. Medial costal process narrowly trigonal, apically pointed, directed ventrally-distally. Distal costal process reduced to very small protrusion. Distal membranous lobe of valva elongated, narrow, directed distally. Sacculus broad, its basal process narrow and long, only slightly shorter than valva, apically pointed. Distal costal process unilobate, finger-like, straight, directed distally. Aedeagus almost straight, slightly narrowed medially. Basal diverticulum of vesica short, broadly conical with rounded tip, membranous. $1^{\text {st }}$ medial diverticulum broad, sack-like, membranous; $2^{\text {nd }}$ medial diverticulum short and broad, covered with numerous short but robust cornuti of various size; $3^{\text {rd }}$ medial diverticulum with broad base and elongated and strongly narrowed distal part, its outer surface covered with numerous short but robust cornuti of various size; $4^{\text {th }}$ medial diverticulum small, membranous; $5^{\text {th }}$ medial diverticulum large, almost globular, its distal half with a broad cluster of short but robust cornuti of various size; proximal half of $5^{\text {th }}$ medial diverticulum membranous, with small area of granulation proximally. Basal plate of vesica ejaculatorius large and heavily sclerotized, broadly trigonal with slightly curved outer margin. Female genitalia (Fig. 51). Papillae anales broad, trapezoidal with rounded corners, setose. Apophyses long and thin, apophyses anteriores one third shorter than apophyses posteriores. Ostium bursae broad. Ductus bursae sclerotized, long, dorso-ventrally flattened, broadened anteriorly, its posterior part with several broad longitudinal subostial folds. Corpus bursae broad, globular, its anterior half membranous. Posterior half of corpus bursae with two elliptical signa of different size and broad, sclerotized, slightly rugose area surrounded by area of shortly spinulose scobination. Appendix bursae sclerotized, short, conical, with broad base.

Etymology. The species is dedicated to Dr. Axel Hausmann, the head of the Department of Entomology of ZSM (Munich, Germany).

Distribution. North Thailand (Chiang Mai Province) (ČERnÝ \& Pinratana 2009, as Barsine yuennanensis).

\section{Barsine yuennanensis subgroup}

Diagnosis. The subgroup includes species with ciliate male antennae (unlike the bipectinate male antennae of the $B$. hausmanni subgroup), yellow body and wing coloration, and pattern consisting of longitudinal blackish dashes on veins. The male genitalia differ from those of the $B$. hausmanni subgroup in more elongated valva, medial costal process being broader(?) and directed more or less ventrally, and bilobate distal saccular process.

\section{Barsine andromeda Volynkin, Černý \& Huang, sp. nov. \\ (Figs 13-16, 40, 41, 52)}

Type locality. China, Shaanxi, Taibai Shan Mts., $33^{\circ} 53^{\prime} \mathrm{N} 107^{\circ} 49^{\prime} \mathrm{E}$ Type material. Holotype (Figs 13, 40): 今, "China| Shaanxi / Taibai Shan Mts. / $33^{\circ} 53^{\prime} \mathrm{N} 107^{\circ} 49^{\prime} \mathrm{E} /$ April.2000, $1500 \mathrm{~m} / \mathrm{leg}$. Siniaev \& $\mathrm{C}^{\circ}$ ', slide

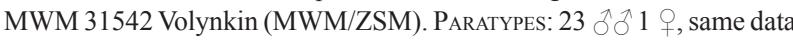
as in the holotype, slide MWM 31543 ( + ) Volynkin (MWM/ZSM); $1 \hat{\delta}$,

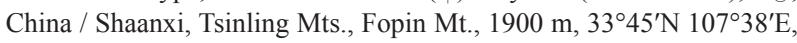
vi.2004, leg. Siniaev \& his team, slide MWM 35761 (む) Volynkin (MWM/ZSM); $3 \hat{\jmath}$, China / Sichuan, Quingchenghoushan Mts., $70 \mathrm{~km}$ NW Chengdu, 1400 m, 14-15.v.2005, leg. S., V., M. Murzin, slide MWM 35666 (ठ) Volynkin (MWM/ZSM); 20 ๙ , altitude 1690 m, 31.v.2019, $31^{\circ} 48^{\prime} 34.52^{\prime \prime} \mathrm{N}, 110^{\circ} 28^{\prime} 46.11^{\prime \prime} \mathrm{E}$, Honghuaduo Village, Shennongjia, Hubei Province, PR China (SCAU); $8 \hat{\delta} \hat{\delta}$, altitude 1523 m, 2.vi.2019, $31^{\circ} 38^{\prime} 20.27^{\prime \prime} \mathrm{N}, 110^{\circ} 25^{\prime} 54.96^{\prime \prime} \mathrm{E}$, Shennongjia, Hubei Province, PR China (SCAU); 1 ô, altitude 785 m, 3.vi.2019, 31 ${ }^{\circ} 22^{\prime} 45.99^{\prime \prime} \mathrm{N}, 110^{\circ} 29^{\prime} 18.62^{\prime \prime} \mathrm{E}$, Chaoshuihe Village, Xingshan County, Yichang City, Hubei Province, PR China (SCAU).

Diagnosis. Barsine andromeda (Figs 13-16) resembles externally $B$. perpallida (Figs 5-7), but can be easily distinguished by its blackish antennae (ochreous yellow in B. perpallida), much darker, yellow body and forewing coloration, and black basal part of the forewing costa. The male genitalia of $B$. andromeda (Figs 40, 41) are similar to those of B. yuennanensis (Figs 42,43) and B. eurydi$c e$ (Fig. 44), but differ from B. yuennanensis in distally broadened uncus, much broader juxta, narrower medial costal process having a strongly curved outer margin and directed ventrally (it is directed ventro-distally in $B$. yuennanensis), slightly more robust basal saccular process, slightly narrower distal saccular process, broadly conical membranous $1^{\text {st }}$ medial diverticulum (hook-like curved and granulated in B. yuennanensis), the presence of two subdiverticula of the $2^{\text {nd }}$ medial diverticulum (in B. yuennanensis there is only one subdiverticulum of the $2^{\text {nd }}$ medial diverticulum), the presence of only granulation on $2^{\text {nd }}$ medial diverticulum (in B. yuennanensis the $2^{\text {nd }}$ medial diverticulum has an elongated cluster of short but robust cornuti of various size), and longer distal section of the $3^{\text {rd }}$ medial diverticulum. Compared to those of $B$. eurydice, the male genitalia of $B$. andromeda have distally broadened uncus (in B. eurydice it has a uniform width and is slightly curved distally), much broader juxta, narrower medial costal process, distally broader basal saccular process, narrower distal saccular process, broadly conical and membranous $1^{\text {st }}$ medial diverticulum (hook-like curved and granulated in $B$. eurydice), two subdiverticula of the $2^{\text {nd }}$ medial diverticulum (in B. eurydice there is only one subdiverticulum of the $2^{\text {nd }}$ medial diverticulum), granulation 
only on the $2^{\text {nd }}$ medial diverticulum (in B. eurydice the $2^{\text {nd }}$ medial diverticulum has an elongated cluster of small short cornuti of various size), and longer distal section of the $3^{\text {rd }}$ medial diverticulum. The female genitalia of $B$. andromeda (Fig. 52) differ from those of B. yuennanensis (Fig. 53) in its broader ostium bursae, broader posterior section of ductus bursae, more rugose posterior sclerotized section of corpus bursae, and longer appendix bursae. Compared to those of B. eurydice (Fig. 54), the female genitalia of $B$. andromeda have broader anterior and posterior ends of ductus bursae, and slightly larger appendix bursae.

Description. Adult (Figs 13-16). Forewing length $19.5-20.0 \mathrm{~mm}$ in males (19.5 $\mathrm{mm}$ in holotype) and 20.0 $\mathrm{mm}$ in females. Antennae blackish, male antennae ciliate, female antennae filiform. Body and forewing ground color dark yellow. Pattern absent. Forewing costa black basally and subbasally. Hindwing pale yellow. Male genitalia (Figs 40, 41). Uncus narrow, laterally flattened, broadened distally, with claw-like tip. Tuba analis broad, membranous, subscaphium broad and setose. Tegumen short and narrow. Juxta large, broad, X-shaped. Vinculum short, more or less V-shaped. Valva broad basally, strongly narrowed distally. Medial costal process narrow, trigonal, with curved outer margin, directed ventrally. Distal costal process absent. Distal membranous lobe of valva narrow, short, directed distally. Sacculus broad, its basal process long, robust, curved dorsally, and pointed apically. Distal saccular process bilobate, its dorsal lobe short, blunt, directed dorsally-distally; distal lobe of distal saccular process elongated, with blunt apex, directed distally. Aedeagus slightly curved medially and broadened distally. Basal diverticulum of vesica short, broad, globular, membranous. $1^{\text {st }}$ medial diverticulum broadly conical with rounded apex, membranous. $2^{\text {nd }}$ medial diverticulum elongated, narrow, granulated, with one medial and one basal short diverticula. $3^{\text {rd }}$ medial diverticulum broadened basally, its distal section elongated, and narrowed, its inner surface granulated, while outer surface covered with short but robust cornuti of various size. $4^{\text {th }}$ medial diverticulum short, broad, covered with short but robust cornuti of various size. $5^{\text {th }}$ medial diverticulum short, broad, globular, covered with short but robust cornuti of various size. Basal plate of vesica ejaculatorius large and heavily sclerotized, broadly trigonal with slightly curved outer margin. Female genitalia (Fig. 52). Papillae anales broad, trapezoidal with rounded corners, setose. Apophyses long and thin, of equal length. Ostium bursae broad. Ductus bursae sclerotized, elongated, dorso-ventrally flattened, slightly broadened anteriorly and posteriorly, its posterior part with several broad longitudinal subostial folds. Corpus bursae short, globular, its anterior half membranous. Posterior half of corpus bursae with one elliptical signum with medial groove, and sclerotized, rugose area surrounded by area of weak, shortly spinulose scobination. Appendix bursae sclerotized, short, curved, with broad base, situated postero-laterally.

Etymology. In the ancient Greek mythology, Andromeda was the daughter of the Aethiopian king Cepheus and his wife Cassiopeia, famous for her beauty. The species name refers to its pure and beautiful delicate wings. Noun in apposition.

Distribution. Central and South West China (Shaanxi, Hubei and Sichuan Provinces).

\section{Barsine yuennanensis (Daniel, 1952)}

(Figs 20-22, 42, 53)

Miltochrista (Barsine) perpallida yuennanensis Daniel, 1952: 79, pl. 2, fig. 35. Type locality: "Nord Yuennan: Li-kiang" [= China, Yunnan, Lijiang].

Type material examined. HoLOTYPe (Figs 21, 42): $\delta$, "[China, Yunnan, Lijiang] Li-kiang ca. 2000m / Prov. Nord-Yuennan / 9.VII.1934, H. Höne" // “ Type / Milt. perpallida / ssp. yuennani / Daniel” // “ ‘’”, slide AV1846 Volynkin (ZFMK). PARATYPES: 50 7 90 , same locality and collector as in the holotype, but 16.v. $\left(1\right.$ ), 18.v. $\left(1\right.$ ), 30.v. $\left(3 \delta^{7}\right)$, 2.vi.

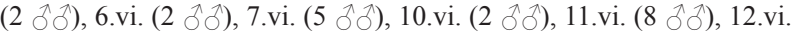

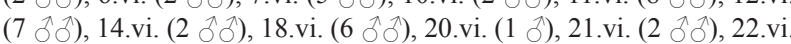

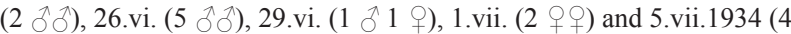
우), slide AV1847 일 Volynkin (ZFMK); 1 , same locality and collector, but 11.vi.1934, slide MWM 31630 Volynkin (MWM/ZSM).

Other material examined. 7 , [China, Yunnan, Lijiang] Li-kiang, ca. 2000 m, Prov. North Yuennan, H. Höne, 20.v. (đ), 2.vi. (ð), 12.vi.

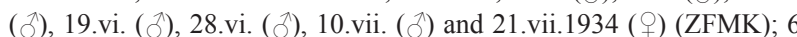
ô ${ }^{2}$, Li-kiang [Lijiang] (China), Province North Yunnan, H. Höne, 28.v., 8.vi., 17.vi., 18.vi., 22.vi. and 6.vii.1935 (ZFMK); 1 9, same locality and collector, but 1.vi.1935, slide MWM 31631 ( + ) Volynkin (MWM/ZSM); 1

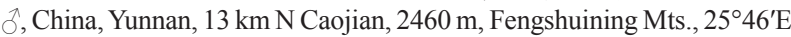
990'소, 20-30.vi.1999, slide MWM 31549 Volynkin (MWM/ZSM).

Diagnosis. Forewing length $16.5-18.5 \mathrm{~mm}$ in males and $19.0-20.0 \mathrm{~mm}$ in females. This species has two forms, striped one (Figs 21, 22) with blackish suffusion along veins, and typical one (Fig. 20) with transverse lines consisting of short longitudinal blackish dashes on veins. Barsine yuennanensis is very similar externally to B. hausmanni (Figs 17-19) and B. dao (Figs 25-28) and can be distinguished from the latter by slightly paler fore- and hindwing coloration only. Compared to $B$. hausmanni, it has ciliate male antennae (bipectinate in $B$. hausmanni), paler coloration, shorter and narrower dashes of transverse lines (longer, broader and more diffuse in $B$. hausmanni), and the antemedial and medial lines well separated from each other (whereas in B. hausmanni those are connected in the cell). The male and female genitalia of B. yuennanensis (Figs 42, 53) are most similar to those of B. nigrovena (Figs 43, 54) and B. eurydice (Fig. 44). The differences are listed in the diagnosis of $B$. nigrovena and B. eurydice.

Distribution. China (Yunnan) (DANIEL 1952, FANG 2000). The record from Thailand (ČERnÝ \& PinRATANA 2009) belongs to B. hausmanni.

\section{Barsine nigrovena (Fang, 2000), comb. nov.} (Figs 23, 24, 43, 54)

Miltochrista nigrovena Fang, 2000: 88 (original description in Chinese), 537 (original description in English), text fig. 55 (male genitalia), pl. II, fig. 4 (adult). Type locality: [China, Hubei], "Hubai, Xingshan, $1260 \mathrm{~m}$.

Type material examined. HoLотуPE (Fig. 23): "Hubei, Xingshan, Longmenhe / 1260m / Chinese Academy of Sciences [in Chinese]" (printed) // "1993.VI.16 / leg. Jian Yao (by light trap) [in Chinese]" (printed) // "L0068" (handwritten) // "HOLOTYPE" (printed) // "Miltochrista / nigrovena / Fang" (handwritten) // " $\mathrm{O}$ ”" (printed) // "IOZ(E) 208773" (printed) (IZCAS). The genitalia slide of the holotype is lost. 
PARATYPe: 9 , "Hubei, Xingshan, Longmenhe / 1380m / Chinese Academy of Sciences [in Chinese]" (printed) // "1993.VII.18, leg. Shi-mei Song [in Chinese]" (printed) // "ALLOTYPE" (printed) // "IOZ(E) 208774" (printed) (IZCAS).

Other material examined. 3 , altitude $785 \mathrm{~m}, 3 . v i .2019$, $31^{\circ} 22^{\prime} 45.99^{\prime \prime} \mathrm{N}, 110^{\circ} 29^{\prime} 18.62^{\prime \prime} \mathrm{E}$, Chaoshuihe Village, Xingshan County,
Yichang City, Hubei Province, PR China, preparations in glycerol by Huang (SCAU); 1 , China, 1000-1300 m, Shaanxi, Quinling Mts, Xunyangba (6 km E), 23.v.-13.vi.1998, I.H. Marshal leg. (CKC); 1 , China, Sichuan, Quingchenghoushan Mts., 70 km NW Chengdu, 1400m, 1-7.vi.2005, leg. S., V. \& M. Murzin, slide MWM 35662 Volynkin (MWM/ZSM); 1 , Frontière orientale du Thibet, Chasseurs indigènes

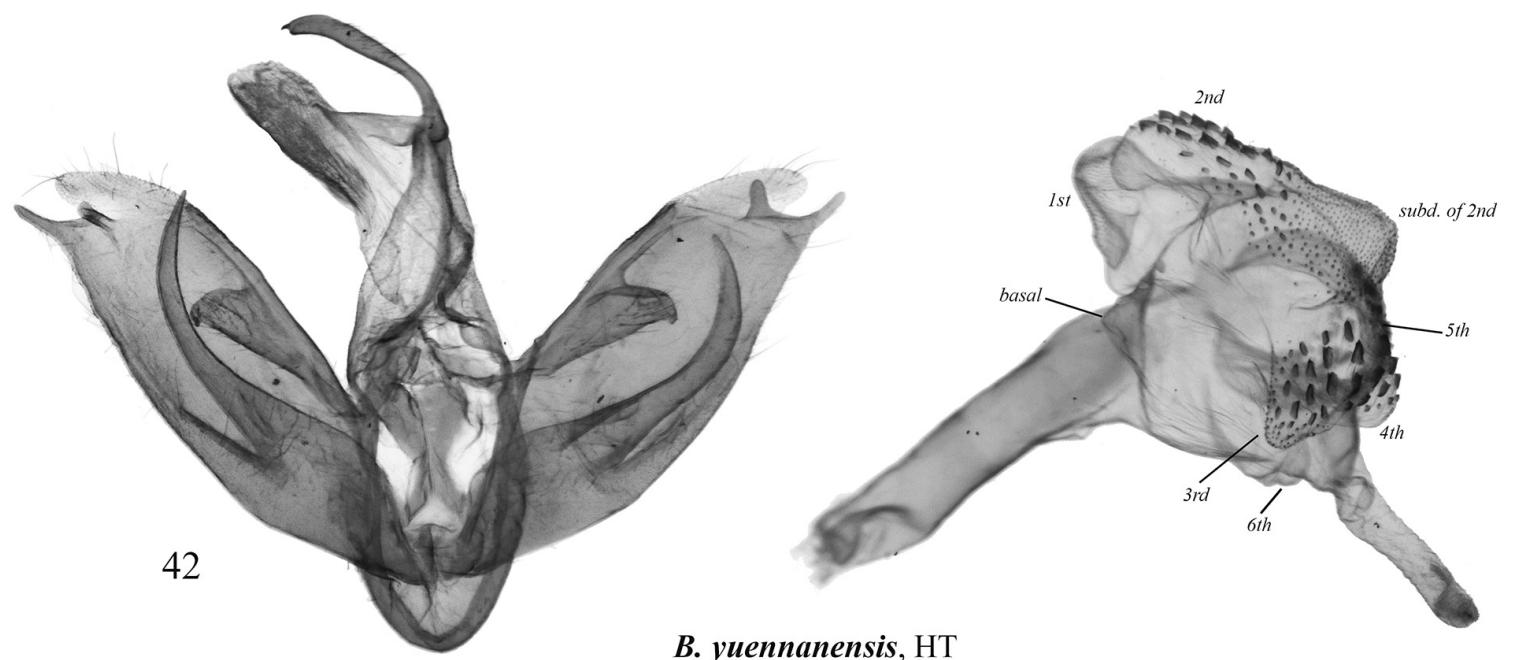

China, Yunnan Prov., Lijiang, slide AV1846
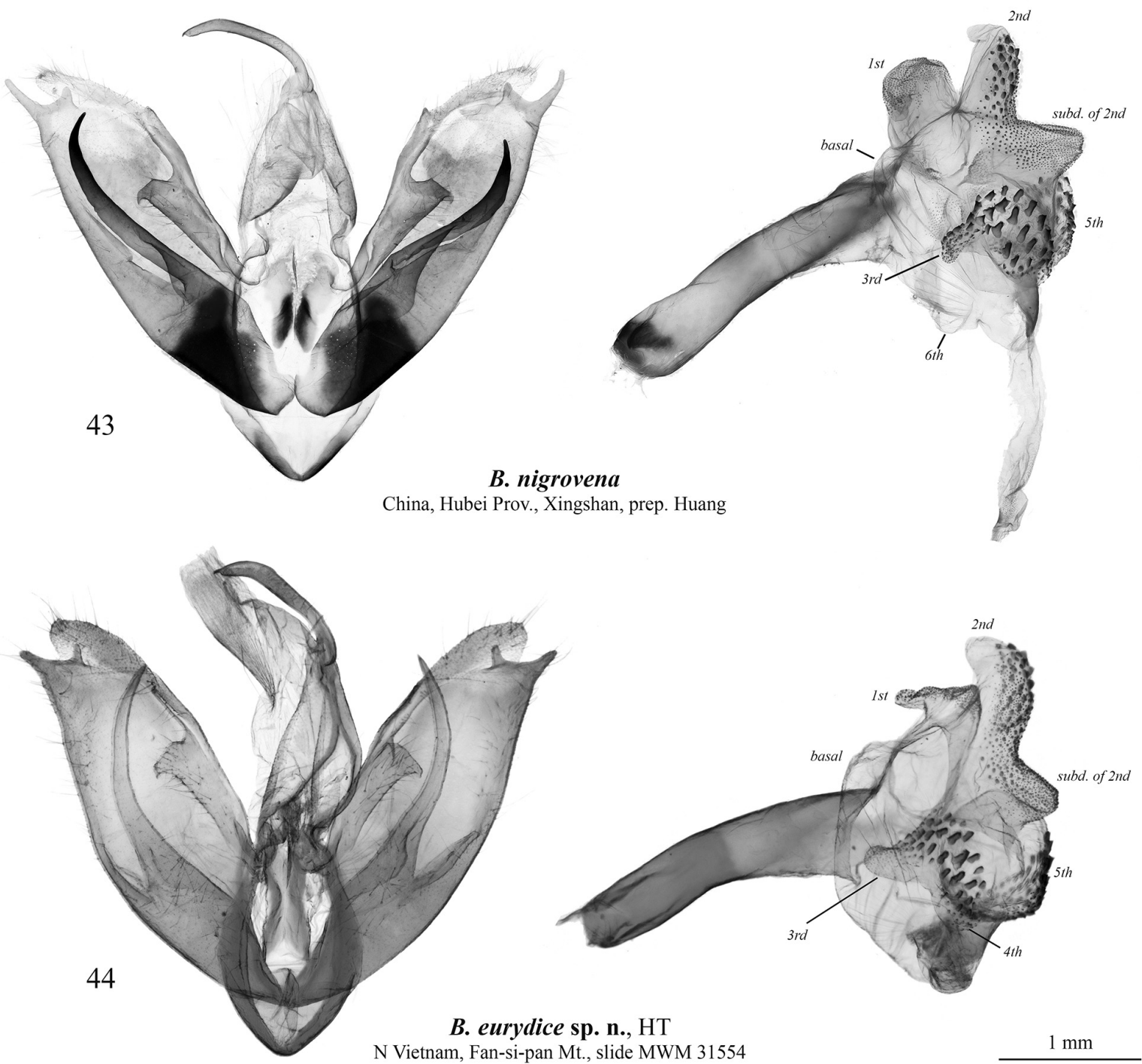

Figs 42-44. Barsine spp., male genitalia. 42 - B. yuennanensis (Daniel, 1952), holotype, China, Yunnan, slide AV1846 Volynkin. 43 - B. nigrovena (Fang, 2000), China, Hubei, prep. Huang. 44 - B. eurydice sp. nov., holotype, N Vietnam, slide MWM 31554 Volynkin. 
du P. Déjean 1906 [eastern border of Tibet, Native collectors of P. P. Déjean] // Ex Oberthür coll. Brit. Mus. 1927-3., NHMUK010604588, slide NHMUK010313508 Volynkin (NHMUK).

Diagnosis. Forewing length $16.5-19.0 \mathrm{~mm}$ in males and $17.0-21.0 \mathrm{~mm}$ in females. Male of B. nigrovena (Fig. 23) can be easily distinguished from other congeners by the presence of broad blackish shades in postmedial and submarginal areas of both wings. Female of $B$. nigrovena (Fig. 24) is similar to that of the striped form of B. yuennanensis (Fig. 22), but differs clearly in its broader forewing, bright yellow forewing ground colour (pale yellow in $B$. yuennanensis) with broader blackish suffusion along veins and blackish cilia of both wings. The male genitalia of $B$. nigrovena (Fig. 43) are similar to those of B. yuennanensis (Fig. 42), but differ in distally narrower uncus, shorter and basally broader juxta, larger vinculum being more or less V-like (smaller and U-like in B. yuennanensis), broader medial costal process directed ventrally (in B. yuennanensis it is narrower and directed ventrally-distally), slightly larger distal costal process, slightly shorter $2^{\text {nd }}$ medial diverticulum bearing smaller cornuti, narrow and more prominent subdiverticulum of the $2^{\text {nd }}$ medial diverticulum, and slightly narrower tip of the $3^{\text {rd }}$ medial diverticulum. The male genitalia of $B$. nigrovena are also similar to those of B. eurydice (Fig. 44), but can be distinguished by their weaker uncus, shorter and slightly broader juxta, basally narrower valva, slightly larger distal costal process, slightly narrower distal membranous lobe of valva, slightly longer distal lobe of the distal saccular process, smaller basal diverticulum of vesica, slightly shorter $2^{\text {nd }}$ medial diverticulum with slightly larger subdiverticulum, and the tip of the $3^{\text {rd }}$ medial diverticulum bearing small cornuti (it is granulated in $B$. eurydice). In the female genitalia, $B$. nigrovena (Fig. 54) differs from B. yuennanensis (Fig. 53) in ductus bursae being less broadened anteriorly, and larger and more heavily sclerotized signum. Compared to those of B. eurydice (Fig. 55), the female genitalia of B. nigrovena have narrower sclerotized posterior area of corpus bursae and more heavily sclerotized signum.

Distribution. Central and South West China: Hubei (FANG 2000), Shaanxi and Sichuan Provinces (new records).

Remark. The holotype genitalia slide is lost.

\section{Barsine eurydice Volynkin \& Černý, sp. nov.} (Figs 29, 30, 44, 55)

Type locality: N Vietnam, Mt. Fan-si-pan, N side, Chapa, $22^{\circ} 15^{\prime} \mathrm{N}$ $103^{\circ} 45^{\prime} \mathrm{E}, 2250 \mathrm{~m}$.

Type material. Holotype (Figs 29, 44): ^ै, "Vietnam (N) / Mt. Fan-si-pan, N-side / Chapa, $22^{\circ} 15^{\prime} \mathrm{N} 103^{\circ} 45^{\prime} \mathrm{E} / 2250 \mathrm{~m}, 26 . I V .1995$ / leg. Sinjaev \& loc. coll.", slide MWM 31554 Volynkin (MWM/ZSM). ParaTYPES: VIETNAM: 62099 , same data as in the holotype, slide MWM 31555 (†) Volynkin (MWM/ZSM); 16 of 16 ㅇ, N Vietnam, $1600 \mathrm{~m}, \mathrm{Mt}$. Fan-si-pan (North), Cha-pa, primary forest, $22.17^{\circ} \mathrm{N} 103.44^{\circ} \mathrm{E}, 20-30$. iv.1995, leg. V. Sinjaev \& local collectors (MWM/ZSM); 1 i 1 , same locality and collectors, but 20-30.vi.1995 (MWM/ZSM); 1 4 9 , , N Vietnam, Mt. Fan-si-pan, W side, Chapa, $22^{\circ} 20^{\prime} \mathrm{N} 103^{\circ} 40^{\prime} \mathrm{E}, 1600-1800$ m, iv.1995, leg. Sinjaev \& loc. collector, (MWM/ZSM); 1 , Vietnam (N), Mts Fan-si-pan, W side, Chapa, $22^{\circ} 20^{\prime} \mathrm{N} 103^{\circ} 40^{\prime} \mathrm{E}, 1600-1800 \mathrm{~m}$, iv.1994, leg. Sinajev \& loc. coll. (MWM/ZSM); 204 + 9 , same locality and collectors, but 15-25.iv.1995 (MWM/ZSM); 1 s, same locality and collectors, but ix.1995 (MWM/ZSM); 1 + , N Vietnam, 16[00]-1800 m,
Mt. Fan-si-pan (West), Cha-pa, ix.1994, 22.20 ${ }^{\circ} \mathrm{N} 103.40^{\circ} \mathrm{E}$, sec. forest / agrocenosis, Sinjaev \& loc. coll. (MWM/ZSM); 533 우, N Vietnam Mt. Fan-si-pan, Cha-pa, $22.15^{\circ} \mathrm{N} 103.46^{\circ} \mathrm{E}, 8-29 . v .1993,2400 \mathrm{~m}, \mathrm{NN}$, leg. Sinjaev \& Simonov, ex coll. A. Schintlmeister (MWM/ZSM); 1 त 1 , $\mathrm{N}$ Vietnam, $1400 \mathrm{~m}$, Mai-chau, primary forest, $40 \mathrm{~km}$ SE Mocchau, $20.50^{\circ} \mathrm{N} 104.50^{\circ} \mathrm{E}, 7-15 . i v .1995$, leg. Sinjaev \& local collectors (MWM/ZSM); 3 ô, North Vietnam, Tam Dao (sec. forest), $60 \mathrm{~km} \mathrm{NW}$ Hanoi, $1200 \mathrm{~m}\left(21.34^{\circ} \mathrm{N} 105.20^{\circ} \mathrm{E}\right), 1-5 . v .1993$, leg. Sinajev \& Simonov (MWM/ZSM).

Diagnosis. Barsine eurydice (Figs 29, 30) is similar externally to $B$. ruficollis (Figs 31,32), but differs in its slightly larger size, darker, ochreous yellow body and forewing coloration (pale yellow in B. ruficollis), and the absence of a red subbasal subcostal stroke on forewing (present in B. ruficollis). The male genitalia of B. eurydice (Fig. 44) are most similar to those of $B$. yuennanensis (Fig. 42) and B. nigrovena (Fig. 43), but can be distinguished by broader medial costal process directed ventrally (in $B$. yuennanensis it is narrower and directed ventrally-distally), slightly smaller lobes of the distal saccular process, broader basal diverticulum of vesica, slightly smaller cornuti on the $2^{\text {nd }}$ medial diverticulum, and longer distal section of the $3^{\text {rd }}$ medial diverticulum. Compared to those of $B$. nigrovena, the male genitalia of the new species have more robust uncus, longer and narrower juxta, basally broader valva, smaller distal costal process, slightly broader distal membranous lobe of valva, slightly shorter distal lobe of the distal saccular process, larger basal diverticulum of vesica, slightly longer $2^{\text {nd }}$ medial diverticulum with slightly smaller subdiverticulum, and granulated tip of the $3^{\text {rd }}$ medial diverticulum (bearing small cornuti in $B$. nigrovena). The female genitalia of $B$. eurydice (Fig. 55) differ from those of B. yuennanensis (Fig. 53) in slightly shorter ductus bursae, more heavily sclerotized and more rugose posterior section of corpus bursae, and rounded signum (elliptical in B. yuennanensis); from B. nigrovena (Fig. 54) it differs in broader sclerotised area of the posterior section of corpus bursae, and smaller, round signum (larger and grain-shaped in B. nigrovena).

Description. Adult (Figs 29, 30). Forewing length 19.5$20.0 \mathrm{~mm}$ in males (19.5 $\mathrm{mm}$ in holotype) and 21.0-22.0 $\mathrm{mm}$ in females. Male antennae ciliate, female antennae filiform. Head ochreous yellow. Thorax ochreous yellow, patagia red. Abdomen pale ochreous basally and dark ochreous yellow distally. Forewing ground color ochreous yellow. Pattern black. Subbasal small black dot. Antemedial and medial line oblique, consist of short strokes on veins. Postmedial line smoothly curved, consists of short strokes on veins. Subterminal area with blackish suffusion on veins. Costa black in subbasal area. Cilia ochreous yellow. Hindwing pale, creamy. Cilia pale yellowish. In females black pattern significantly reduced. Male genitalia (Fig. 44). Uncus narrow and laterally flattened, with claw-like tip; its distal third curved. Tuba analis broad, membranous, subscaphium broad and setose. Tegumen short and narrow. Juxta long, X-shaped. Vinculum short, broadly V-shaped with rounded tip. Valva broad basally, narrowed distally. Medial costal process broadly trigonal, with curved outer margin, directed ventrally. Distal costal process absent. Distal membranous lobe of valva moderately broad, short, 
directed distally. Sacculus broad, its basal process long, robust, curved dorsally and pointed apically. Distal saccular process bilobate, its dorsal lobe short, narrow, with blunt apex, directed dorsally-distally; distal lobe of distal saccular process elongated, with blunt apex, directed distally. Aedeagus slightly curved medially and broadened distally.
Basal diverticulum of vesica short, very broad, rounded, membranous. $1^{\text {st }}$ medial diverticulum hook-like curved, granulated. $2^{\text {nd }}$ medial diverticulum elongated, narrow, with one basal short diverticulum, granulated. $3^{\text {rd }}$ medial diverticulum broadened basally, its distal section short, narrowed, granulated; basal part of $3^{\text {rd }}$ medial diverticu-
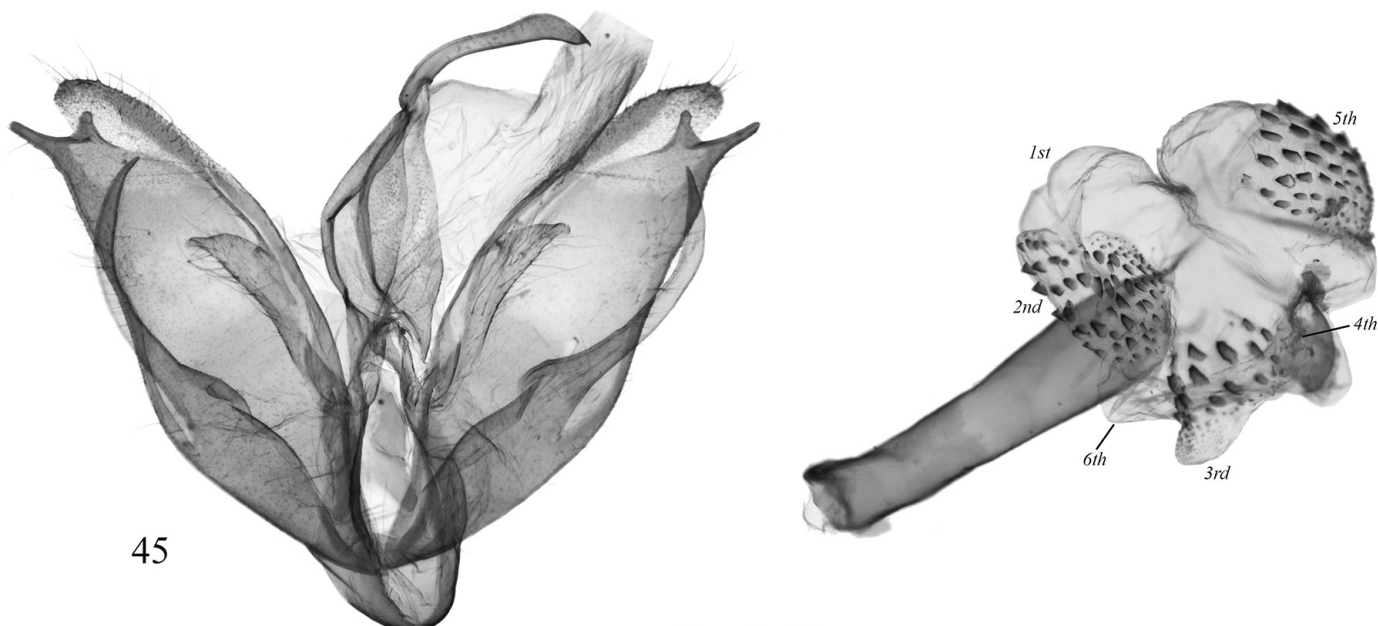

B. ruficollis

China, NW Yunnan, Fengshuining Mts, slide MWM 31544

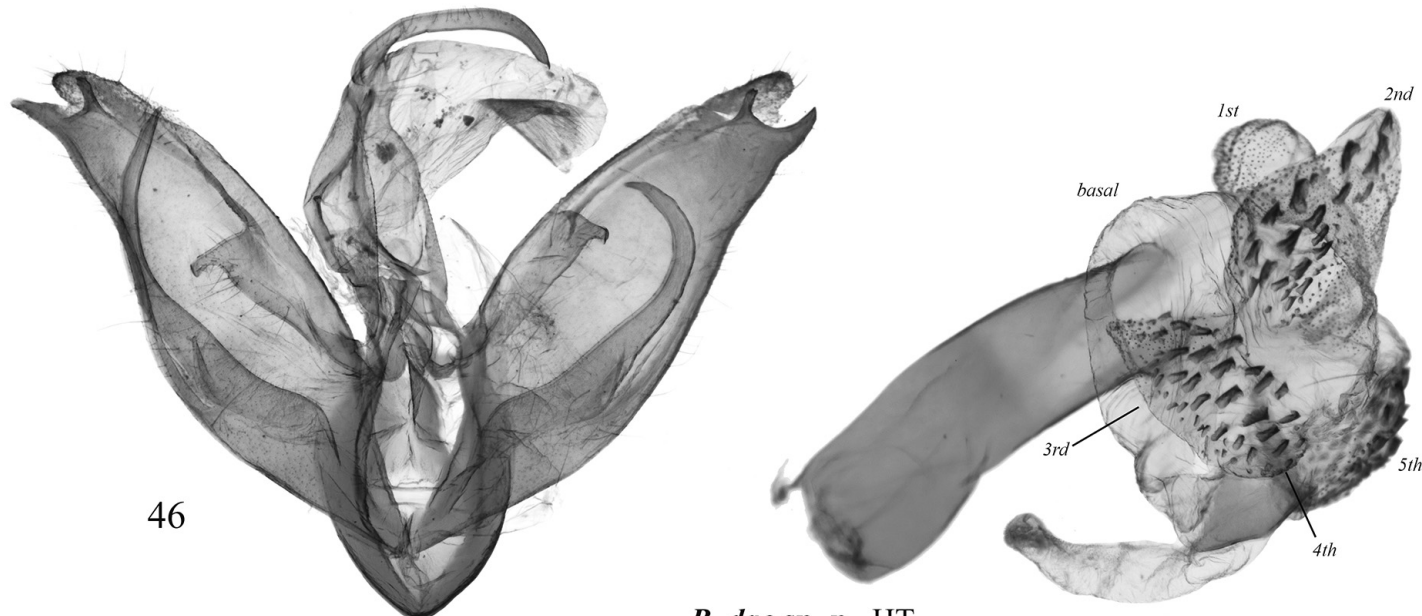

B. dao sp. n., HT

N Vietnam, Fan-si-pan Mt., slide MWM 31552

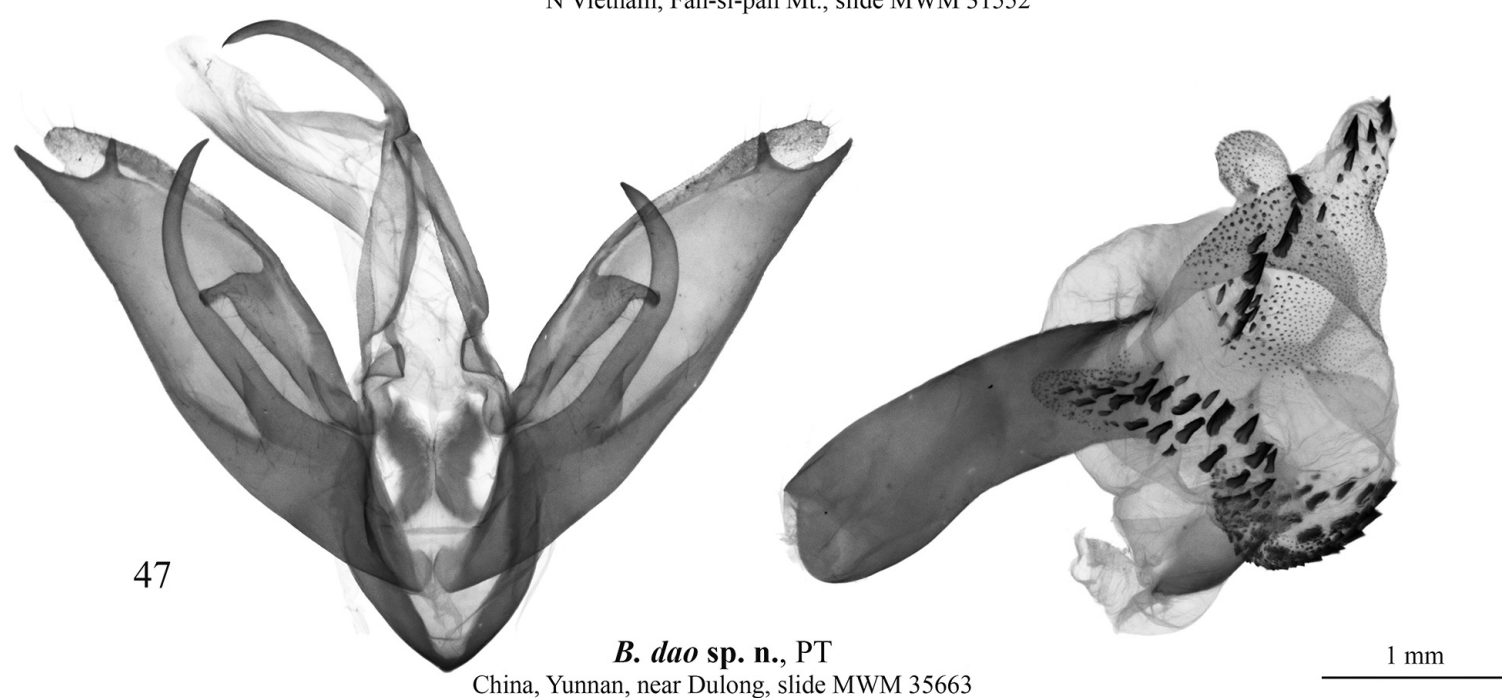

Figs 45-47. Barsine spp., male genitalia. 45 - B. ruficollis (Fang, 1991), China, Yunnan, slide MWM 31544 Volynkin. $46-47$ - B. dao sp. nov.: $46-$ holotype, N Vietnam, slide MWM 31552 Volynkin; 47 - paratype, China, Yunnan, slide MWM 35663 Volynkin. 
lum covered with short but robust cornuti of various size. $4^{\text {th }}$ medial diverticulum short, broad, covered with short but robust cornuti of various size. $5^{\text {th }}$ medial diverticulum short, broad, globular, covered with short but robust cornuti of various size. Basal plate of vesica ejaculatorius large and heavily sclerotized, broadly trigonal with slightly curved outer margin. Female genitalia (Fig. 55). Papillae anales broad, trapezoidal with rounded corners. Apophyses long and thin, of equal length. Ostium bursae broad. Ductus bursae sclerotized, elongated, dorso-ventrally flattened, slightly broadened anteriorly, its posterior part with several broad longitudinal subostial folds. Corpus bursae short, globular, its anterior half membranous. Posterior half of corpus bursae with one rounded signum and sclerotized, rugose area surrounded by area of weak, shortly spinulose scobination. Appendix bursae sclerotized, shortly conical, curved, situated postero-laterally.

Etymology. In the ancient Greek mythology, Eurydice was an oak nymph, one of the daughters of Apollo and the beloved wife of Orpheus. The species name refers to its beautiful appearance and forest inhabitation. Noun in apposition.

Distribution. The species is known from North Vietnam (provinces of Lào Cai, Hòa Bình and Vĩnh Phúc) only.

\section{Barsine ruficollis (Fang, 1991), comb. nov.}

(Figs 31, 32, 45, 56)

Miltochrista ruficollis Fang, 1991: 392, 397, fig. 11. Type locality: [China], "Lushui, Yunnan, $2500 \mathrm{~m}$ ".

Type material examined. HоLOTYPE: N, "Miltochrista / ruficollis / Fang" // "Holotype" // " J" // "IOZ(E) 208665" // "1981.VI.4 / leg. Xue-zhong Zhang [in Chinese]" // "Yunnan, Lushui, Yaojiaping [in Chinese] / 2500 $\mathrm{m} /$ Chinese Academy of Sciences [in Chinese]" / "L.-0050" (IZCAS). Remark. The holotype genitalia slide is lost. PARATYPE: ${ }^{\circ}$ "Allotype" “o" / "IOZ(E) 208666" / "1981.VI.2 / light trap [in Chinese] / leg. Su-bai Liao [in Chinese]" / "Yunnan, Lushui, Yaojiaping [in Chinese] / $2500 \mathrm{~m}$ / Chinese Academy of Sciences [in Chinese]" (IZCAS).

Other material examined. $12 \approx 699$, China, Prov. Yunnan, Yunlong, Fengshuining Mts., 13 km N of Caojian, 2460 m, 20.v.-9.vi.1999, leg. Dr. Ronald Brechlin (MWM/ZSM); 62 4 9 9 , China / Yunnan Prov. (NW), Dali Bai autonom. pref.; Yunlong County; Fengshuining Mts., $2460 \mathrm{~m}, 13 \mathrm{~km} \mathrm{~N}$ of Coajian, 10-20.v.1999, 25.46 ${ }^{\circ} \mathrm{N} 99.06^{\circ} \mathrm{E}$, leg./ex coll. Dr. R. Brechlin, slides MWM 31544 (ð), MWM 31545 () Volynkin (MWM/ZSM); 1 q, China, prov. Yunnan, Dali Bai aut. pref., Yunlong, $13 \mathrm{~km}$ N of Coajian, Fengshuining Mts., 2460 m, 10-23.vi.1999, leg. Dr. Ronald Brechlin (MWM/ZSM).

Diagnosis. Forewing length $18.0-19.0 \mathrm{~mm}$ in males and 19.0-19.5 mm in females. Barsine ruficollis (Figs 31, 32) is similar externally to B. eurydice (Figs 29,30), but can be easily distinguished by its slightly smaller size, pale yellow body and forewing coloration (ochreous yellow in B. eurydice), and the presence of a red subbasal subcostal stroke on forewing (absent in $B$. eurydice). Male genital capsule of B. ruficollis (Fig. 45) is most similar to that of B. yuennanensis (Figs 42, 43), but differs in its uncus being strongly broadened subapically, smaller medial costal process, and distal saccular process having narrower base. The vesica of $B$. ruficollis differs clearly from that of $B$. yuennanensis in the absence of a basal diverticulum, much broader and rounded $1^{\text {st }}$ medial diverticulum (narrower and hook-like curved in B. yuennanensis), much broader and shorter $2^{\text {nd }}$ medial diverticulum having no subdiverticulum, narrower cluster of cornuti of the $3^{\text {rd }}$ medial diverticulum, shorter and granulated $4^{\text {th }}$ medial diverticulum (bearing cornuti in B. yuennanensis), much larger $5^{\text {th }}$ medial diverticulum, and larger $6^{\text {th }}$ medial diverticulum. In the female genitalia, $B$. ruficollis (Fig. 56) differs from B. yuennanensis (Fig. 53) in longer ductus bursae being narrower anteriorly and having longer longitudinal subostial folds, much broader and more rugose posterior sclerotized area of corpus bursae, and smaller signum. Compared to those of $B$. eurydice (Fig. 55), the female genitalia of B. ruficollis have significantly longer ductus bursae, less rugose posterior sclerotized area of corpus bursae, and smaller signum.

Distribution. China (Yunnan) (FANG 1991, 2000).

\section{Barsine dao Volynkin, Černý \& Huang, sp. nov.} (Figs 25-28, 46, 47, 57)

Type locality. N Vietnam, 1600m, Mt. Fan-si-pan (N), Cha-pa, $22.17^{\circ} \mathrm{N}$ $103.44^{\circ} \mathrm{E}$.

Type material. HоLотYPE (Figs 25, 46): 今, "N-Vietnam 1600m / Mt. Fansi-pan (Nord) / Cha-pa, Primärurwald [primary forest] / 22.17"N 103.44"E /25-30.III.1995 / leg. V. Sinjaev \& / A. Schintlmeister", slide MWM 31552 Volynkin (MWM/ZSM). PARATYPES: VIETNAM: $201 \%$, same data as in the holotype, slide MWM 35664 ( same locality, but 20-30.iv.1995, leg. V. Sinjaev \& local collectors, slide MWM 31553 ( + ) Volynkin (MWM/ZSM); 1 , North Vietnam, Prov. Lao Cai, Plateau Nr. 1, 2170 m, Fansipan, leg. Binh, coll. S. Löffler, slide MWM 31548 ( Mts., W side, near Cha-pa, 1600-1800 m, 22 ${ }^{\circ} 20^{\prime} \mathrm{N} 103^{\circ} 40^{\prime} \mathrm{E}$, V.1995, leg. local collectors, ex coll. Schintlmeister (MWM/ZSM); 1 , same locality, but iv.1995, leg. Sinjaev \& loc. coll., ex coll. Schintlmeister (MWM/ZSM); $2 \delta^{2}$, N Vietnam, $1600 \mathrm{~m}$, Mt. Fan-si-pan (North), Cha-pa, primary forest, $22.17^{\circ} \mathrm{N} 103.44^{\circ} \mathrm{E}, 20-30 . v i .1995$, leg. V. Sinjaev \& local collectors (MWM/ZSM). CHINA: 1 , China, Yunnan, Dulong County, $60 \mathrm{~km} \mathrm{SE}$ Wen Shan, 10 km SE Maguan, 2400 m, 30.iii.1999, leg. G. Müller, slide MWM 35663 ( an Miao Autonomous County, Mts. Daweishan, 2100 m, 18.viii.2018, leg. Si-yao Huang (SCAU); $5 \hat{o}$, same locality and collector, but 19.viii.2018 (SCAU); 1 , China, Guangdong, Ruyuan Yao Autonomous County, Mts. Nanling, 997 m, 6.v.2017, leg. Min Wang (SCAU); 1 \% , same locality, but 11.v.2018, leg. Si-yao Huang \& Fu-hong Wei (SCAU).

Diagnosis. Barsine dao (Figs 25-28) is very similar externally to the typical form of B. yuennanensis (Figs 21, 23), but can be distinguished by its slightly darker fore- and hindwing coloration, and slightly longer dashes of transverse lines. In addition, in $B$. dao the dashes of the antemedial and medial lines are connected in the cell, whereas in B. yuennanensis the antemedial and medial lines are well separated from each other. Nevertheless, reliable identification is often possible based on the genitalia structures only. The male genitalia of $B$. dao (Figs 46, 47) differ clearly from those of $B$. yuennanensis (Figs 42, 43) in distally narrower uncus, slightly broader juxta, more elongated valva, strongly narrowed tip of the medial costal process (evenly trigonal in B. yuennanensis), narrower dorsal lobe of the distal saccular process, longer and apically narrower distal lobe of the distal saccular process, and the vesica structure. Compared to that of B. yuennanensis, vesica of $B$. dao has much larger basal diverticulum, globular $1^{\text {st }}$ medial diverticulum (hook-like curved in B. yuennanensis), much broader $2^{\text {nd }}$ medial diverticulum without subdiverticulum and covered with a longitudinal cluster of larger 


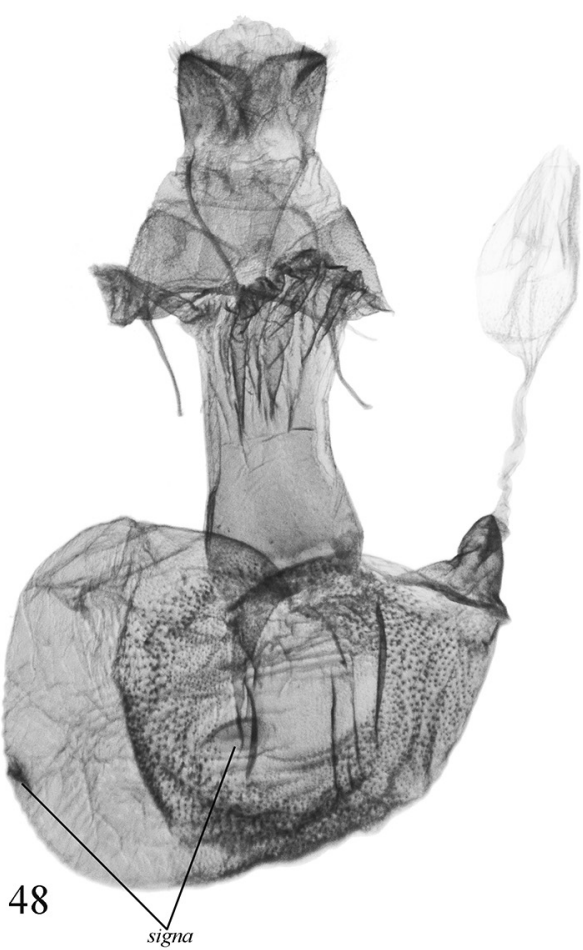

B. biformis sp. n., PT

N Thailand, Nan Prov., slide ZSM Arct. 155 / 2017

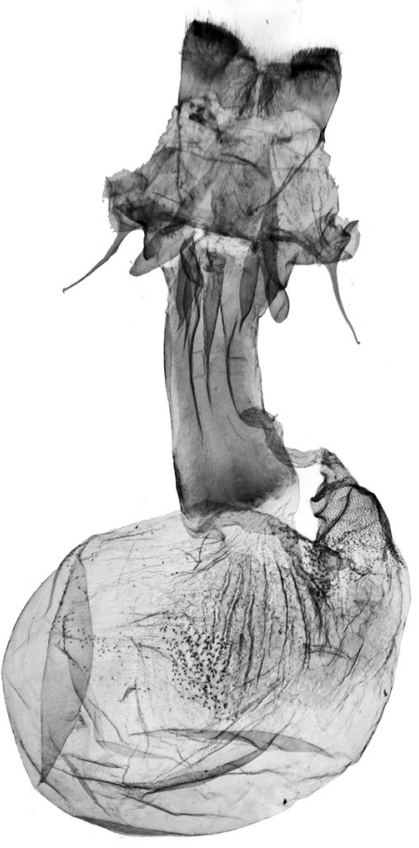

49

B. perpallida, ST of porthesioides NE India, Sikkim, slide NHMUK010315755

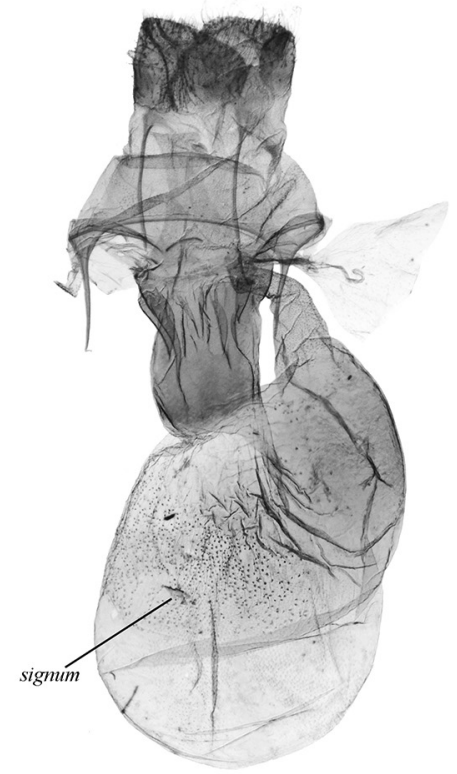

50

B. laszloi sp. n., PT

Nepal, Annapurna Himal, slide MWM 35760

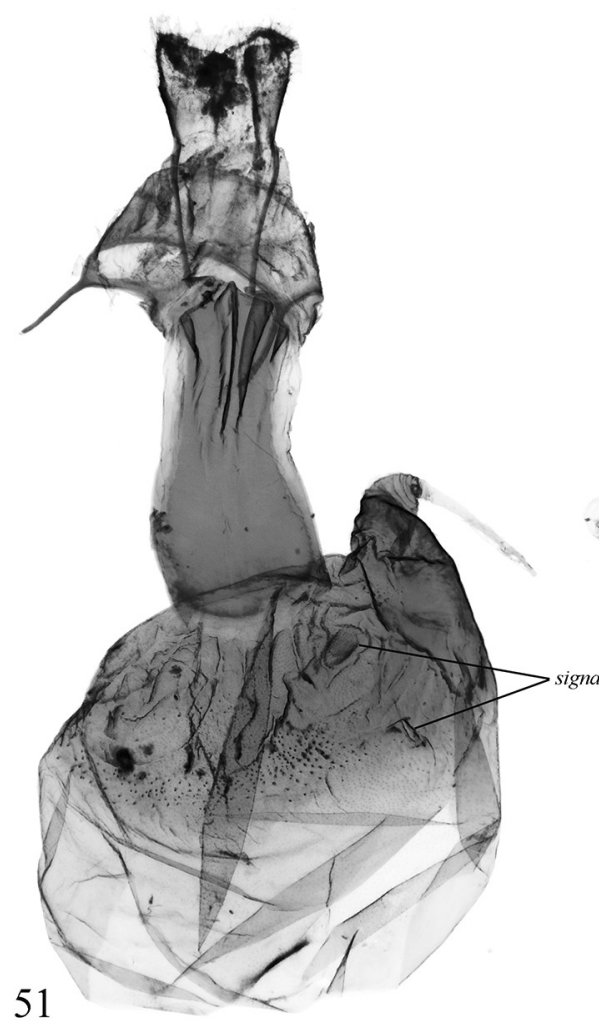

B. hausmanni sp. n., PT

N Thailand, Chiang Mai Prov., Doi Phahompok Mt., slide MWM 31547

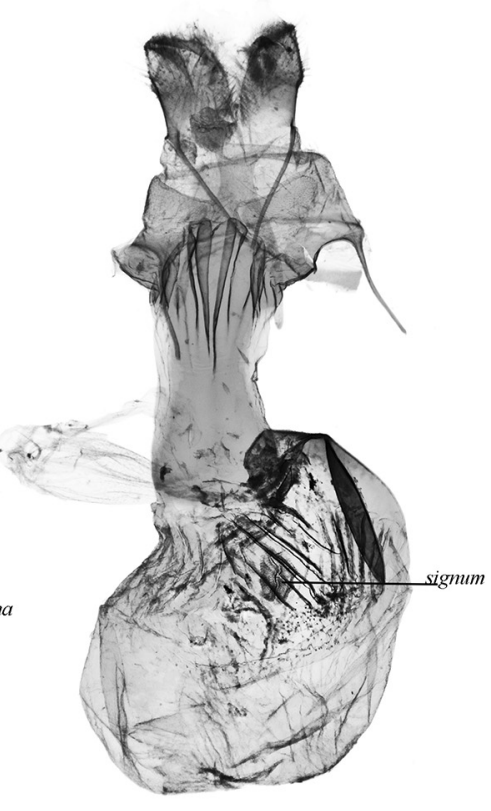

52

B. andromeda sp. n., PT

China, Shaanxi, Taibai Shan Mt., slide MWM 31543

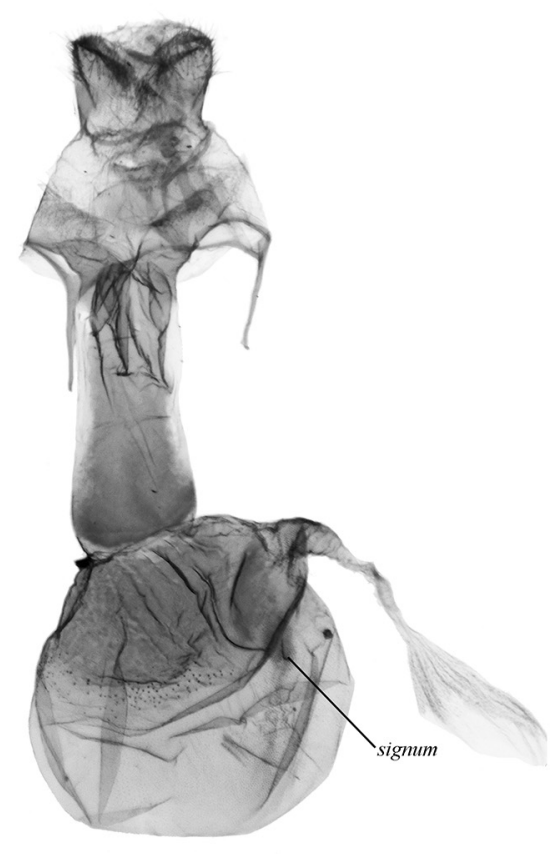

53

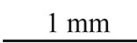

\section{B. yuennanensis, PT}

China, Yunnan, Lijiang, slide AV 1847

Figs 48-53. Barsine spp., female genitalia. 48 - B. biformis sp. nov., paratype, Thailand, slide ZSM Arct. 155 / 2017 Volynkin. 49 - B. perpallida (Hampson, 1900), syntype of Diacrisia porthesioides Rothschild, 1910, India, slide NHMUK010315755 Volynkin (CNHMUK). 50 - B. laszloi sp. nov., paratype, Nepal, slide MWM 35760 Volynkin. 51 - B. hausmanni sp. nov., paratype, Thailand, slide MWM 31547 Volynkin. 52 - B. andromeda sp. nov., paratype, China, Shaanxi, slide MWM 31543 Volynkin. 53 - B. yuennanensis (Daniel, 1952), paratype, China, Yunnan, slide AV1843 Volynkin. 
cornuti, much larger $3^{\text {rd }}$ medial diverticulum covered with larger cornuti, broader $4^{\text {th }}$ medial diverticulum covered with larger cornuti, and broader $5^{\text {th }}$ medial diverticulum covered with larger cornuti. The female genitalia of $B$. dao (Fig. 57) differ from those of B. yuennanensis (Fig. 53) in horseshoe-like concavity of ostium bursae (absent in

54

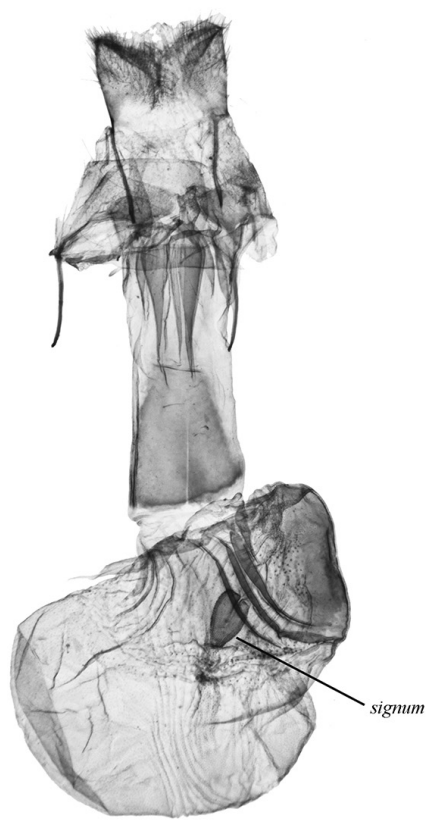

B. nigrovena

China Sichuan Prov. slide NHMUK010313508

56

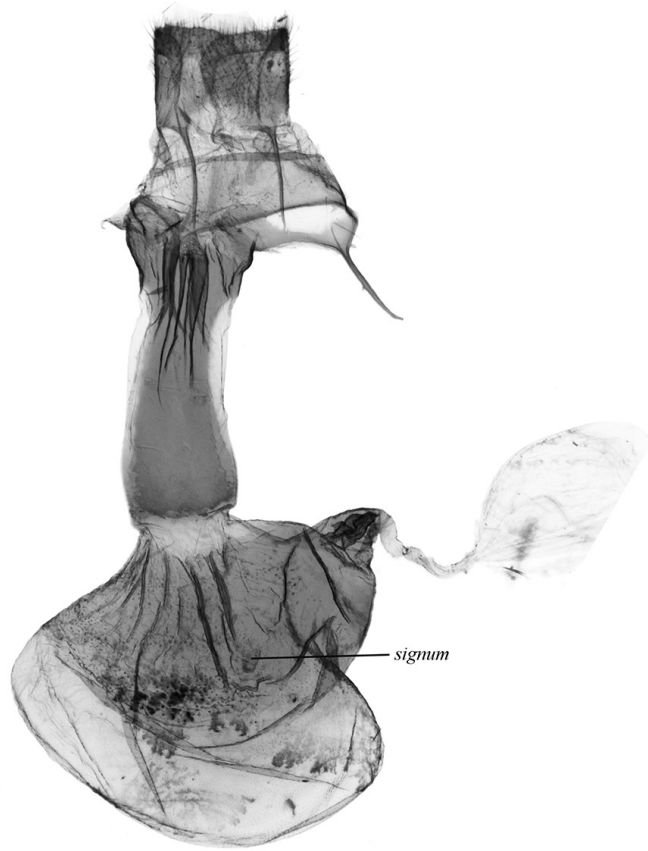

\section{B. ruficollis}

China, NW Yunnan, Fengshuining Mts, slide MWM 31545
B. yuennanensis), ductus bursae being slightly broadened anteriorly, broader and more rugose sclerotized posterior section of corpus bursae surrounded by a broad area of strong shortly spinulose scobination (in B. yuennanensis the scobination is weaker, its area is narrower and present only anteriorly), and larger appendix bursae.
55

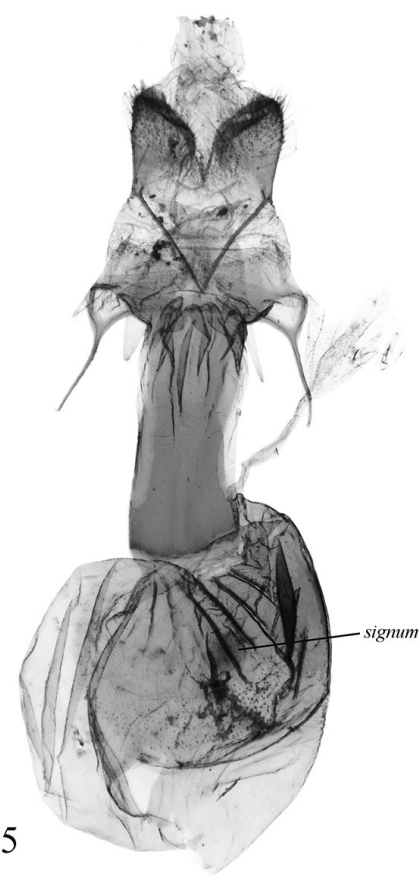

B. eurydice sp. n., PT

$\mathrm{N}$ Vietnam, Fan-si-pan Mt., slide MWM 31555

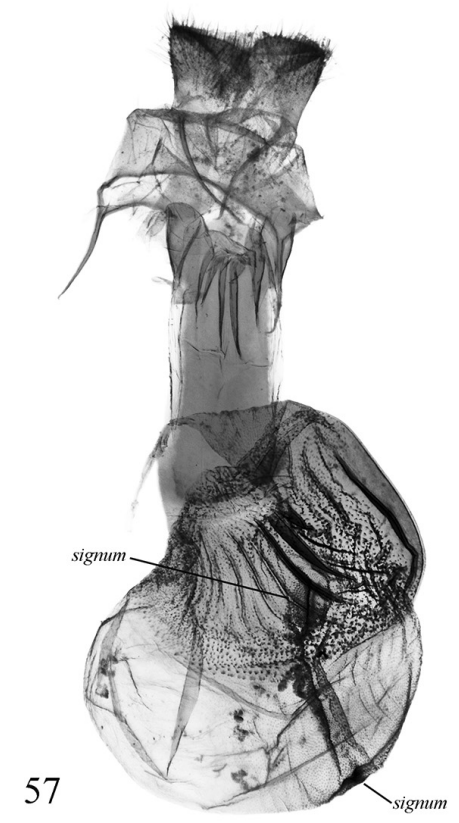

B. dao sp. n., PT

N Vietnam, Fan-si-pan Mt., slide MWM 31553

Figs 54-57. Barsine spp., female genitalia. 54 - B. nigrovena (Fang, 2000), China, Sichuan, slide NHMUK010313508 Volynkin (CNHMUK). 55 - B. eurydice sp. nov., paratype, N Vietnam, slide MWM 31555 Volynkin. 56 - B. ruficollis (Fang, 1991), China, Yunnan, slide MWM 31545 Volynkin. 57 B. dao sp. nov., paratype, N Vietnam, slide MWM 31553 Volynkin. 
Description. Adult (Figs 25-28). Forewing length 15.5$18.5 \mathrm{~mm}$ in males (18.5 $\mathrm{mm}$ in holotype) and 20.0-21.0 $\mathrm{mm}$ in females. Antennae of both sexes ciliate, with longer ciliae in males. Head and thorax from ochreous yellow to bright yellow; abdomen pale ochreous basally and ochreous yellow or bright yellow distally. Forewing ground color from ochreous yellow to bright yellow. Forewing pattern black. Antemedial and medial lines slightly curved, consist of elongated dashes on veins, situated closely to each other, sometimes their dashes connected in the cell; postmedial line curved, consist of elongated dashes on veins; subterminal area with a series of longitudinal dashes of various length on veins. In females pattern more diffuse, longitudinal dashes thinner and often fused to each other. Cilia as forewing ground color. Hindwing pale ochreous yellow. Male genitalia (Figs 46, 47). Uncus narrow, laterally flattened, curved basally and subapically, with short claw-like tip. Tuba analis broad, membranous, subscaphium broad and setose. Tegumen short and moderately broad. Juxta large, broad, X-shaped. Vinculum short, more or less V-shaped, slightly curved laterally. Valva elongated, narrowed distally. Medial costal process broadly trigonal, with slightly curved outer margin; its distal part strongly tapered with blunt tip, directed ventrally. Distal costal process absent. Distal membranous lobe of valva narrow, short, apically rounded, directed distally. Sacculus broad, its basal process long, robust, curved dorsally, and pointed apically. Distal saccular process bilobate, its dorsal lobe short, narrow, with blunt tip, directed dorsally-distally; distal lobe of distal saccular process elongated, narrowly trigonal, with tapered apex, directed distally. Aedeagus slightly curved medially and broadened proximally. Vesica broad, its basal diverticulum short but very broad, membranous. $1^{\text {st }}$ medial diverticulum small, globular, granulated. $2^{\text {nd }}$ medial diverticulum large, conical, with broad basal part, bearing a longitudinal narrow cluster of short but robust trigonal cornuti of various size, directed distally. $3^{\text {rd }}$ medial diverticulum short, broad, conical, covered with short but robust trigonal cornuti of various size. $4^{\text {th }}$ medial diverticulum short, round, covered with short but robust trigonal cornuti of various size. $5^{\text {th }}$ medial diverticulum large, rounded, covered with short but robust trigonal cornuti of various size. Basal plate of vesica ejaculatorius broadly trigonal, heavily sclerotized. Female genitalia (Fig. 57). Papillae anales broad, trapezoidal with rounded corners, setose. Apophyses long and thin, of equal length. Ostium bursae broad, with a deep horseshoe-shaped ventral concavity. Ductus bursae sclerotized, elongated, dorso-ventrally flattened, slightly broadened anteriorly, its posterior part with several broad longitudinal subostial folds. Corpus bursae short, sack-like, left part of its anterior half membranous, right part weakly granulated and bearing a round signum. Posterior half of corpus bursae sclerotized, with a large elliptical signum having longitudinal concavity; and strongly rugose area broadly surrounded by area of weak, shortly spinulose scobination. Appendix bursae large, conical, sclerotized, curved inwards, situated postero-laterally.

Etymology. In the traditional Chinese philosophy and religion, Dao is the natural order of the universe whose cha- racter one's human intuition must discern in order to realize the potential for individual wisdom. Noun in apposition. Distribution. The species is known from North Vietnam (Lào Cai Prov.) and the Chinese province of Yunnan.

\section{Acknowledgements}

We express our sincere thanks to the following colleagues for their kind assistance provided during the senior author's studies at their institutions: Dr. Axel Hausmann, Dr. Wolfgang Speidel and Mr. Ulf Buchsbaum (ZSM, Munich, Germany); Dr. Alberto Zilli and Mr. Geoff Martin (NHMUK, London, UK); Dr. Marianne Espeland (ZFMK, Bonn, Germany); and Dr. Wolfram Mey (ZMB, Berlin, Germany); and Prof. Wu Chunsheng (IZCAS, Beijing, China) for his assistance provided during the third author's studies at the IZCAS collection and his help with photographing of the types.

\section{References}

BREMER O. 1864: Lepidopteren Ost-Sibiriens, insbesondere der Amur-Landes, gesammelt von den Herren G. Radde, R. Maack und P. Wulffius. Mémoires de l'Académie Impériale des Sciences de SaintPétersbourg, Série 7 8(1): 1-104, pls. 1-8.

ČERNÝ K. 2016: A contribution to the knowledge of the Miltochrista-Lyclene genus group in South East Asia (Lepidoptera, Erebidae, Arctiinae, Lithosiini). Nachrichten des Entomologischen Vereins Apollo 37(2-3): 93-107.

ČERNÝ K. \& PINRATANAA. 2009: Moths of Thailand, Vol. 6, Arctiidae. Brothers of Saint Gabriel in Thailand, Bangkok, Thailand, 283 pp.

DANIEL F. 1952: Beiträge zur Kenntniss der Arctiidae Ostasiens unter besonderer Berücksichtigung der Ausbeuten von Dr. h. c. H. Höne aus diesem Gebiet (Lep.-Het.). III. Teil: Lithosiinae. Bonner Zoologische Beiträge 3(1-2): 75-90.

FANG C. 1991: Studies of the genus Miltochrista of China (Lepidoptera: Arctiidae: Lithosiinae). Sinozoologia 8: 383-397 (in Chinese, English summary)

FANG C. 2000: Lepidoptera. Arctiidae. Fauna Sinica (Insecta) 19. Science Press, Beijing, 590 pp (in Chinese, English summary).

HAMPSON G. F. 1895: Descriptions of New Heterocera from India. Transactions of the Entomological Society of London 1895(2): 277-315.

HAMPSON G. F. 1900: Catalogue of the Arctiadae (Nolinae, Lithosianae) in the British Museum. Catalogue of the Lepidoptera Phalaenae in the British Museum 2: 1-590.

HAMPSON G. F. 1914: Catalogue of the Amatidae and Arctiadae (Nolinae, Lithosianae) in the collection of the British Museum. Catalogue of the Lepidoptera Phalaenae in the British Museum, Supplement 1: $1-858$.

ICZN 1999: International Code of Zoological Nomenclature. 4th Edition. The International Trust of Zoological Nomenclature, London, $306 \mathrm{pp}$.

MOORE F. 1878: A revision of certain genera of European and Asiatic Lithosiinae, with characters of new genera and species. Proceedings of the Scientific Meetings of the Zoological Society of London 1878: 3-37, pls. 1-3.

ROTHSCHILD W. 1910: Descriptions of new species of Arctianae in the Tring Museum. Novitates Zoologicae 17(2): 172-188, pl. 14.

SINGH J., SINGH N. \& JOSHI R. 2014: A checklist of subfamily Arctiinae (Erebidae: Noctuoidea: Lepidoptera) from India. Records of the Zoological Survey of India 367: 1-76.

STRAND E. 1922: Arctiidae: Subfam. Lithosiinae. Pp. 1-899. In: WAGNER H. (ed.): Lepidopterorum Catalogus. Vol. 26. W. Junk, Berlin.

VOLYNKIN A. V. \& ČERNÝ K. 2016: Barsine deliciosa, a new species from China (Lepidoptera, Erebidae, Arctiinae). Zootaxa 4200(1): $181-191$.

WALKER F. 1854: List of the specimens of lepidopterous insects in the collection of the British Museum. Volume 2. Trustees of the British Museum, London, pp. 279-581. 
